\author{
Laura A. Tesmer* \\ Steven K. Lundy** \\ Sujata Sarkar \\ David A. Fox
}

\section{Th17 cells in human disease}

\author{
Authors' addresses \\ Laura A. Tesmer ${ }^{1, *}$, Steven K. Lundy ${ }^{1, *}$, Sujata Sarkar ${ }^{2}$, David A. Fox ${ }^{1}$, \\ ${ }^{1}$ Division of Rheumatology, Department of Internal \\ Medicine and Rheumatic Disease Core Center, \\ University of Michigan, Ann Arbor, MI, USA. \\ ${ }^{2}$ Division of Rheumatology and the Arizona Arthritis \\ Center Department of Internal Medicine, University of \\ Arizona, Tucson, AZ, USA. \\ Correspondence to: \\ David A. Fox \\ A. Alfred Taubman Health Care Center \\ University of Michigan \\ 1500 East Medical Center Drive \\ Room 3918 \\ Ann Arbor, MI 48109-5358 \\ USA \\ Tel.: +17349365566 \\ Fax: +1 7347631253 \\ e-mail: dfox@med.umich.edu
}

*LAT and SKL contributed equally to this work
Summary: Our understanding of the role of $\mathrm{T}$ cells in human disease is undergoing revision as a result of the discovery of T-helper 17 (Th17) cells, a unique $\mathrm{CD}^{+}$T-cell subset characterized by production of interleukin-17 (IL-17). IL-17 is a highly inflammatory cytokine with robust effects on stromal cells in many tissues. Recent data in humans and mice suggest that Th17 cells play an important role in the pathogenesis of a diverse group of immune-mediated diseases, including psoriasis, rheumatoid arthritis, multiple sclerosis, inflammatory bowel disease, and asthma. Initial reports also propose a role for Th17 cells in tumorigenesis and transplant rejection. Important differences, as well as many similarities, are emerging when the biology of Th17 cells in the mouse is compared with corresponding phenomena in humans. As our understanding of human Th17 biology grows, the mechanisms underlying many diseases are becoming more apparent, resulting in a new appreciation for both previously known and more recently discovered cytokines, chemokines, and feedback mechanisms. Given the strong association between excessive Th17 activity and human disease, new therapeutic approaches targeting Th17 cells are highly promising, but the potential safety of such treatments may be limited by the role of these cells in normal host defenses against infection.

Keywords: T cells, interleukins, autoimmunity, human disease, IL-17, IL-23

\section{Introduction}

Two decades ago Mossman and Coffman (1) proposed that $\mathrm{CD}^{+}{ }^{+} \mathrm{T}$ cells differentiate into two subsets with reciprocal functions and patterns of cytokine secretion, termed T-helper 1 (Th1) and Th2. Th1 cells are characterized by production of interferon- $\gamma$ (IFN- $\gamma$ ) and induce cell-mediated immunity against intracellular pathogens, while Th2 cells produce interleukin-4 (IL-4) and stimulate humoral immunity against parasitic helminths. This paradigm was maintained until 2005, when a third T-cell subset, known as Th17, was identified $(2,3)$. Th17 cells are characterized by production of IL-17 and may have evolved for host protection against microbes that Th1 or Th2 immunity are not well suited for, such as extracellular bacteria and some fungi. While Th17 cells were only recently recognized as a unique Th-cell subset, IL-17 has been known for much longer. Human IL-17 was originally cloned in 1995, and early reports demonstrated multiple

inflammatory and hematopoietic effects on epithelial,
Vol. $223: 87-113$

Vol. 223: 87-113

Printed in Singapore. All rights reserved

Journal compilation (C) 2008 Blackwell Munksgaard

No claim to original US government works

Immunological Reviews

0105-2896 
endothelial, and fibroblastic cells (4-6). These initial studies set the stage for much of what is now known about IL-17. The common theme that holds true for almost every tissue is that IL-17 mediates powerful effects on stromal cells, resulting in production of inflammatory cytokines and recruitment of leukocytes, especially neutrophils, thus creating a link between innate and adaptive immunity. Although Th17 cells play an important role in host defense, they have received considerable attention in recent years primarily because they appear to be the principal mediators of pathogenesis in several autoimmune and inflammatory disorders. The discovery of Th17 cells has opened up a new avenue for research into the etiology and treatment of a broad spectrum of diseases. The role of Th17 cells in this diverse group of diseases is the subject of this review.

\section{Biology of ThI7 cells}

In the 3 years since Th17 cells were recognized as a unique Th subset, data on the biology of these cells have emerged at an astonishing pace. From these data, it is becoming increasingly evident that both Th cell differentiation, and the cytokine networks which control it, are remarkably complex and tightly regulated. While work on human Th17 cells initially lagged behind the mouse data, this gap is narrowing with the discovery of many interesting similarities and differences between the two species. Although many of the early principles of mouse Th17 biology have quickly become widely accepted, some of the most basic questions regarding human Th17 cells are still under dispute. Given the wide array of human diseases associated with aberrant Th17 responses and the great amount of interest in targeted therapies, a thorough understanding of Th1 7 biology in both mice and humans will clearly be essential for designing the safest and most effective treatments.

\section{Th17 differentiation}

One of the most interesting and widely studied topics related to Th1 7 cells is the nature of the signals that cause naïve T cells to differentiate along this pathway. When a naïve $\mathrm{CD} 4^{+} \mathrm{T}$ cell is activated, the local cytokine milieu plays an important role in determining which effector lineage that cell will assume, by inducing lineage-specific transcription factors. Naïve $\mathrm{T}$ cells stimulated in the presence of IL-12 become Th1 cells and express the transcription factor T-bet, while those stimulated in the presence of IL-4 become Th2 cells and express the transcription factor GATA-3 (reviewed in 7). Initial studies in mice suggested that IL-23, a heterodimeric cytokine that shares a subunit with IL-12, induced IL-17 expression $(2,3,8,9)$. However, subsequent studies demonstrated that the IL-23 receptor is only expressed on $\mathrm{T}$ cells after activation, and therefore IL-23 can upregulate IL-17 in memory $\mathrm{T}$ cells but cannot act on naïve T cells to induce Th17 differentiation (9). Instead, three groups nearly simultaneously discovered that the key to Th17 differentiation in the mouse is the combination of transforming growth factor- $\beta$ (TGF- $\beta$ ) and IL-6 (10-12). In addition, tumor necrosis factor- $\alpha$ (TNF- $\alpha$ ) and IL-1 $\beta$ can further enhance mouse Th17 differentiation, but only in the presence of TGF- $\beta$ and IL-6 (12-14) (Table 1). This discovery was a surprise, because TGF- $\beta$ is well known to inhibit most Tcell responses as well as to induce differentiation of forkhead box protein 3 (FoxP3)-expressing regulatory $\mathrm{T}$ cells (Tregs) (reviewed in 15). These conflicting effects of TGF- $\beta$, as an inducer of both anti-inflammatory Tregs and pro-inflammatory Th1 7 cells, raise a number of interesting questions about the role of TGF- $\beta$ in disease as well as the relationship between these two very different T-cell subsets. In mice, Tregs can serve as a source of TGF- $\beta$ for naïve Th17 differentiation, and one study found that Tregs themselves can convert into Th17 cells in the presence of IL-6 (16). Importantly, Th17 cells appear to be resistant to the suppressive effects of Tregs $(17,18)$. These results significantly complicate our current understanding of the role of Tregs in inflammatory disease, suggesting that Tregs may be unable to suppress Th17-mediated inflammation and might actually augment it.

Differentiation of Th1 and Th2 cells follows similar rules in humans as in mice; Th17 differentiation, in contrast, may not be as conserved. IL-1 $\beta$, which seems to play only a supporting role in mouse Th17 development, is the most effective inducer of IL-17 expression in human naïve T cells. IL-6 and IL-23 induce a small amount of IL-17 alone and greatly enhance Th1 7 differentiation in the presence of IL-1 $\beta(19,20)$. Thus, IL-23 and IL-1 $\beta$ may play a more important role in humans than in mice, although the potential role of IL-23 in human Th17 differentiation is still unclear, as other groups have found IL-23 to have no effect on naïve human T cells (21). In mice, IL-23 plays an important role in Th1 7 effector function, but the mechanism is still under debate. IL-23 upregulates IL-17 production and promotes survival and expansion of activated or memory Th17 cells in vitro, although it is not absolutely necessary $(8,12,22)$. Recently, D. Cua et al. (personal communication) reported interesting in vivo results showing that IL-23R positive and negative Th17 cells survive and produce IL-17 equally well, but only IL-23R-positive Th17 cells migrate to the site of inflammation in a mouse model of multiple sclerosis (MS). Much more work is needed in both mouse and human to fully understand how IL-23 supports Th17-mediated pathology, especially considering that 
Table 1. Th1 7 cytokine biology in mouse and human

\begin{tabular}{lll}
\hline & Human & Mouse \\
\cline { 2 - 2 } (A) Regulators of Th I7 cells & & \\
TGF- $\beta$ & $\downarrow / \uparrow$ & $\uparrow \uparrow$ \\
IL-6 & $\uparrow \uparrow$ & $\uparrow \uparrow$ \\
IL-I $\beta$ & $\uparrow \uparrow$ & $\uparrow$ \\
TNF- $\alpha$ & $\uparrow$ & $\uparrow$ \\
IL-23 & $\uparrow \uparrow$ & $\uparrow \uparrow$ \\
IL-2I & $?$ & $\uparrow \uparrow$ \\
IL-4 & $\downarrow$ & $\downarrow$ \\
IFN- $\gamma$ & $\downarrow$ & $\downarrow$ \\
IL-I2 & $\downarrow$ & $\downarrow$ \\
IL-27 & $\downarrow$ & $\downarrow$ \\
(B) Effector cytokines & & \\
IL-I7A & ++ & ++ \\
IL- I7F & + & + \\
IL-2I & $?$ & + \\
TNF- $\alpha$ & + & + \\
IL-22 & + & + \\
IL-26 & + & $?$ \\
IFN- $\gamma$ & + & + \\
IL-I0 & $?$ & + \\
\hline
\end{tabular}

In part (A) cytokines which have been shown to regulate the differentiation or effector function of Th 17 cells are listed. $\uparrow \uparrow$, central role in Th 17 development; $\uparrow$, minor role in Th 17 development; $\downarrow$, inhibitory effect on Th 17 development. In part (B) cytokines which are produced directly by Th17 cells are listed $(+$ and - mean yes and no). ++ , predominant cytokine produced by ThI7 cells; + , cytokines produced by a subset of ThI 7 cells; ?, insufficient data.

neutralizing antibodies targeting the shared IL-12/IL-23 subunit are already under clinical investigation in multiple inflammatory diseases.

Another interesting topic of debate is the role of TGF- $\beta$ in human Th17 biology. Several studies have shown that TGF- $\beta$, a crucial cytokine for mouse Th17 differentiation, actually inhibits human Th17 development (18-20). These results suggest that a fundamental difference between mouse and human Th17 biology, which could be a major obstacle to translating work from animal models into humans. There is still significant debate in the field, though, and it is too early to completely rule out TGF- $\beta$ as an inducer of human Th17 cells. One concern is that 'naïve' $\mathrm{T}$ cells from human peripheral blood may not be as inexperienced as those in a laboratory mouse, which spends its life protected from exposure to pathogens. In addition, the effects of TGF- $\beta$ are extremely concentration dependent; AY Rudensky et al. (personal communication) found that only low doses will induce Th17 differentiation, while high doses inhibit Th17 development and induce Tregs. This finding becomes especially important when one considers that human $\mathrm{T}$ cells are more sensitive to TGF- $\beta$ than mouse T cells and that TGF- $\beta$ is commonly found in serum used in tissue culture media. A recent report by $\mathrm{D}$. Littman and colleagues found that $\mathrm{T}$ cells from cord blood, which represent a more naïve state than those in adult peripheral blood, do in fact require TGF- $\beta$ to differentiate into Th17 cells (23). These results were confirmed by Volpe et al. who found that TGF- $\beta$, IL-7 $\beta$ and IL-6 induced Th17 differentiation in naïve human $\mathrm{T}$ cells from peripheral blood (24). Additional studies are needed to resolve this debate, and the conclusion will certainly have an impact on our understanding of Th17 development in human disease.

Th1 and Th2 cells are known to antagonize each other, and not surprisingly, IL-12, IFN- $\gamma$, and IL-4 can inhibit Th17 differentiation in both mouse and human (2, 3, 17, 19, 20, $25,26)$. IL-17, however, does not appear to inhibit Th1 or Th2 differentiation or does so very weakly, and so Th1 and Th2 cells typically dominate over Th17 cells (14). This observation explains one of the ways in which TGF- $\beta$ can promote Th17 differentiation, by suppressing production of the inhibitory cytokines IFN- $\gamma$ and IL-4, but TGF- $\beta$ also has direct roles in Th17 differentiation since it is required even in the absence of IFN- $\gamma$ and IL-4 (10-12). TGF- $\beta$ synergizes with IL- 6 to induce expression of the transcription factor ROR $\gamma \mathrm{t}$, a key regulator of Th17 differentiation. In mice, ROR $\gamma \mathrm{t}$ is both necessary and sufficient for IL-17 expression in vitro and in vivo (27). In humans RORC (the human ortholog of ROR $\gamma \mathrm{t}$ ) is induced by IL-1 $\beta$, IL-6, and IL-23, the same cytokines that induce IL-17 $(19,20)$. In addition, RORC expression is restricted to IL-17producing clones (17). Thus, just as T-bet controls the Th1 lineage and GATA-3 controls the Th2 lineage, ROR $\gamma$ t appears to control the Th17 lineage. Still, there are a few unanswered questions. ROR $\gamma t$ is an orphan nuclear receptor with a ligandbinding pocket, suggesting that its activity may be regulated by an unknown ligand. Also, ROR $\gamma$ t has not yet been shown to directly bind to the IL-17 promoter, although a potential binding site was identified (27). Despite these issues, inhibition of ROR $\gamma t$ may be therapeutically useful, and the ligand-binding pocket is an ideal pharmacologic target.

In addition to ROR $\gamma \mathrm{t}$, Th17 development in mice depends on the transcription factor signal transducer and activator of transcription 3 (STAT3), which is activated by IL-6 and IL-23. STAT3 has multiple roles in Th17 development: in activated Th17 cells stimulated with IL-23, it binds directly to the IL-17 promoter and induces IL-17 expression, and in naïve $\mathrm{T}$ cells stimulated with TGF- $\beta$ and IL-6, it is required for induction of ROR $\gamma$ t expression, although it is not yet known if STAT3 binds directly to the ROR $\gamma t$ promoter (28-31). Because both ROR $\gamma t$ and STAT3 are required for IL-17 expression, there may be cooperation between the two transcription factors at the IL-17 promoter. IL-23 also activates STAT4, which is the primary mediator of IL-12 signaling and is required for Th1 
differentiation, yet is still important for IL-23-induced IL-17 production (30). Thus, STAT4 may inhibit Th17 development downstream of IL-12, while also supporting IL-17 expression downstream of IL-23. In addition to STAT3 and STAT4, there are likely to be other transcription factors that are required for Th17 development, such as Smad-2 or Smad-3 downstream of TGF- $\beta$, which may be useful therapeutic targets.

\section{Cytokines expressed by Th 17 cells}

When $\mathrm{T}$ cells differentiate, they begin to express specific cytokines, such as IFN- $\gamma$ in Th1 and IL-4 in Th2, which act in an autocrine feedback loop to further promote differentiation, thus giving activated T cells self-sufficiency to move out of the lymphoid tissue and traffic to the site of inflammation while continuing to develop. Similarly, mouse Th17 cells specifically express IL-21 soon after activation, and autocrine IL-2 1 plays an important role in ROR $\gamma \mathrm{t}$ and IL-17 expression. IL-21 can also partially replace IL-6 during Th17 differentiation, giving established Th17 cells the ability to promote further Th17 development in neighboring cells. IL-23 in combination with TGF- $\beta$ can also induce ROR $\gamma$ t and IL-17 expression, but only after IL-6 or IL-2 1 induces IL-23 receptor expression (32-36). Thus IL-6, IL-21, and IL-23 act sequentially: first IL-6 upregulates IL-21, then both IL-6 and IL-21 upregulate IL-23 receptor, and finally IL-23 appears to upregulate effector function and pathogenicity in Th17 cells through an unknown mechanism. It has yet to be demonstrated what role IL-2 1 plays in human Th1 7 differentiation, although human IL-21 has been shown to upregulate IL-17 production and T-cell proliferation and to counteract suppression by Tregs $(37,38)$.

Th1 7 cells are characterized by production of IL-17, but they also produce other inflammatory cytokines, which can play an important role in disease (Table 1). IL-17, or IL-17A, is one member of a family of six cytokines known as IL-17A through F. Th17 cells specifically express IL-17F in addition to IL-17A. IL-17A and IL-17F are closely related, with 55\% amino acid identity as well as a common receptor (39). IL-17A and IL-17F are both homodimeric cytokines, but recent evidence shows that human and mouse $\mathrm{T}$ cells also produce an IL-17A/F heterodimer that has potent inflammatory effects $(40,41)$. Currently, much less is known about the inflammatory effects of IL-17F than IL-17A, but given their high degree of similarity and possible redundancy, it may be important to measure, as well as to target, both IL-17A and IL-17F in disease. Other pro-inflammatory cytokines produced by both mouse and human Th17 cells include TNF- $\alpha$, a well-known mediator of inflammatory disease, IL-22, and IL-26 (19-21, 42-45). Much less is known about IL-22 and IL-26, members of the IL-10 family, which promote innate, non-specific immunity in cells outside of the immune system. Studies in keratinocytes and colonic myofibroblasts show that IL-22 induces anti-microbial proteins, defensins, acute-phase proteins, inflammatory cytokines, chemokines, and hyperplasia (46-48). Others have found, however, that IL-22 protects hepatocytes during acute liver inflammation (49); thus, IL-22 produced by Th17 cells may enhance inflammation or limit tissue damage induced by IL-17, depending on the type of tissue.

Unexpectedly, a subset of Th17 cells co-expresses IFN- $\gamma$, particularly in humans, in whom as many as half of all the IL- $17^{+}$cells also express IFN- $\gamma(19-21,43)$. These doublepositive cells seem to contradict the idea that Th17 cells are a unique subset distinct from Th1 cells, and these cells are particularly problematic to explain, given that IFN- $\gamma$ has been shown to inhibit IL-17 expression. However, human Th cell differentiation is known to be more flexible than that in mouse, and it is not uncommon to see IL-4/IFN- $\gamma$ double-positive T cells in humans, although it is rare in mice. It is not yet clear if these cells represent a stable phenotype or a transitional phase, undergoing a switch from Th17 to Th1 or vice versa. Although there are no data on the specific role of these double-positive cells, both IFN- $\gamma$ and IL-17 are important mediators of inflammation, and cells that produce both cytokines are likely to contribute to pathogenesis in certain environments. Another unexpected finding is the existence of many Th17 cells co-expressing IL-10. IL-10 is an anti-inflammatory cytokine produced by a number of different cell types. T-cell sources of IL-10 are generally thought to include Th2 cells and various types of Tregs, but Th1 cells have also been found to secrete IL-10 in certain conditions and to thereby limit their own inflammatory effects $(50,51)$. In mice, the combination of TGF- $\beta$ and IL- 6 , which synergize to induce IL-1 7 production, also synergize to induce IL-10, with the end result that half of the $\mathrm{IL}_{-}-17^{+}$cells co-express $\mathrm{IL}-10$ and half of the $\mathrm{IL}-10^{+}$ cells co-express IL-17 $(52,53)$. IL-10 produced by Th17 cells may serve an important protective function by limiting inflammation and tissue damage normally caused by IL-17. In fact, Th17 cell-derived IL-10 was found to play an important role in limiting Th17-driven inflammation in a mouse model of MS (52). It is not yet known whether human Th17 cells ever co-express IL-10 or what role IL-10 plays in limiting human Th17-driven disease.

\section{Trafficking of Th 17 cells}

Inflammation and pathogenesis induced by Th17 cells is a result of the pro-inflammatory cytokines these cells produce, but another important and often overlooked factor is the 
chemokines and chemokine receptors that mediate trafficking of activated $\mathrm{T}$ cells into diseased tissue. In addition, each T-cell subset typically expresses a unique pattern of chemokine receptors, creating a way to specifically identify and target different subsets. Several reports have found that human and mouse Th17 cells express the chemokine receptor CCR6, including memory cells from healthy peripheral blood and inflamed tissue as well as in vitro primed naïve T cells $(17,19$, $43,54)$. Although not all CCR $6^{+}$cells are Th1 7 cells, it appears that within the $\mathrm{CCR}^{+}$population, those that co-express CXCR3 are either Th1or IFN $\gamma$-IL-17 double positive, while those that co-express CCR 4 are classical Th17 expressing only IL-17. In addition, the majority of the RORC expression was restricted to the $\mathrm{CCR}^{+}{ }^{+} \mathrm{CCR} 4^{+}$population, with a small amount in the $\mathrm{CCR}^{+}{ }^{+} \mathrm{CXCR} 3^{+}$population (43). CCR6 mediates homing to skin and mucosal tissues and has been shown to play an important role in recruitment of pathogenic $\mathrm{T}$ cells in many inflammatory diseases now associated with IL-17, including psoriasis, inflammatory bowel diseases (IBD), allergic asthma and rheumatoid arthritis (RA) (54-58). Interestingly, the CCR6 ligand CCL20 is expressed by Th17 cells and is upregulated in stromal cells by IL-17, allowing Th17 cells in inflamed tissues to attract additional Th17 and Th1 cells (20, $54,59,60)$. Another group found human memory Th17 cells within the $\mathrm{CCR} 2{ }^{+} \mathrm{CCR} 5{ }^{-}$population and Th1 cells within the $\mathrm{CCR} 2{ }^{+} \mathrm{CCR} 5^{+}$population (61). It is not yet clear whether the $\mathrm{CCR}{ }^{+} \mathrm{CCR} 4^{+}$population overlaps with the $\mathrm{CCR} 2{ }^{+} \mathrm{CCR} 5{ }^{-}$, but the combination of all four markers may be a powerful tool for isolating human Th17 cells from blood and sites of inflammation to further characterize their biology.

We have learned a great deal about Th17 biology in a very short period of time, including some key details: Th17 cells differentiate in the presence of TGF- $\beta$ and IL- 6 in mice or IL- $1 \beta$ and IL- 6 in humans, depend on the transcription factor ROR $\gamma \mathrm{t}$, require IL-23 for effector function, and express the hallmark cytokines IL-17A, IL-17F, and IL-22. Yet there are still many unanswered questions, such as what is the exact role of ROR $\gamma \mathrm{t}$ in Th17 differentiation and how does IL-23 promote Th17 pathogenicity. The relationship between Tregs and Th17 cells as well as the possible pro-inflammatory role of Tregs are also of great interest. A largely unexplored topic is also the role of IL-17 production by cells other than $\mathrm{CD}^{+}{ }^{+} \mathrm{T}$ cells. IL-17 can also be produced by $\mathrm{CD} 8^{+} \mathrm{T}$ cells, $\gamma \delta \mathrm{T}$ cells, and in some cases even natural killer T (NKT) cells, neutrophils, and eosinophils. One of the reasons Th17 cells have gained such attention is that they are implicated in the pathogenesis of many different animal models of disease, and therefore a critical direction for future studies of Th17 cells will be to determine what roles these cells play in human disease, and ultimately how useful or safe they will be as a therapeutic target (Table 2).

\section{ThI 7 cells in rheumatic diseases}

Psoriasis

Psoriasis is a chronic inflammatory disease of the skin characterized by epidermal hyperplasia, dermal angiogenesis, and infiltration of monocytes, dendritic cells (DCs), and T lymphocytes. Evidence points to a role for both Th1 and Th17 cells in the pathogenesis of psoriasis, due to elevated levels of many specific inflammatory cytokines. Th1 cytokines IFN- $\gamma$, IL-2, and IL-18, as well as Th17 cytokines IL-17A, IL-17F, IL-22, IL-26, and TNF- $\alpha$ (which is both a Th1 and a Th1 7 cytokine), are overexpressed in serum and lesional skin $(20,47,62,63)$. The role of IL-17 in the pathogenesis of psoriasis has been further substantiated by increased expression of RORC, IL-6, IL-1 $\beta$, and IL-23 in psoriatic skin as compared with noninvolved skin or skin from healthy individuals (20). Some studies have suggested that IL-15 can also induce IL-17, and it has been shown that neutralizing antibodies to IL-15 can improve psoriasis in a mouse model (64).

Initial studies suggested that psoriasis was a Th1 disease, based on increased expression of the p40 subunit of IL-12. However, many experiments have had to be re-interpreted once it became clear that the IL-12 p40 subunit is also part of IL-23. IL-12 consists of a p40 subunit and a p35 subunit, while IL-23 consists of a p40 subunit and a p19 subunit. Several

\section{Table 2. Evidence for a role of Th17 cells in immune-mediated diseases}

\begin{tabular}{ll}
\hline Rheumatic diseases & \\
Psoriasis & ++ \\
Rheumatoid arthritis & ++ \\
Systemic sclerosis & $+/-$ \\
Systemic lupus erythematosus & $+/-$ \\
Non-rheumatic autoimmunity & \\
Multiple sclerosis & + \\
Autoimmune myocarditis & $+/-$ \\
Type I diabetes & $+/-$ \\
Autoimmune thyroiditis & $+/-$ \\
Asthma and allergic diseases & \\
Asthma & ++ \\
Atopic dermatitis & + \\
Contact hypersensitivity & + \\
Other immune-mediated diseases & \\
Inflammatory bowel disease & ++ \\
Periodontal disease & ++ \\
\hline
\end{tabular}

++ , those diseases in which there is substantial and convincing evidence for a role for ThI7 cells in both humans and animal models; + , those diseases in which there is good evidence for a role for ThI 7 cells, either in humans or animal models, but more conclusive studies are needed; + I diseases in which there is very limited evidence suggestive of a possible role for ThI7 cells, but no conclusion can be drawn without substantial additional work. 
studies have now shown that the p40 subunit and the IL-23specific p19 subunit, not the IL-12-specific p35 subunit, are highly expressed in monocytes and DCs in psoriatic skin lesions $(20,63,65,66)$. The role of IL-23 in the induction of dermal changes seen in psoriasis has been confirmed by in vivo studies done in mice. When injected into the skin of the ears, IL-23 induced epidermal hyperplasia and inflammatory cellular infiltration similar to psoriasis, which was mediated by TNF$\alpha$, IL-22, IL-17A, and IL-17F $(42,63)$.

IL-22 is elevated in blood of patients with psoriasis (47), and IL-22R, which is expressed on epithelial cells, regulates proliferation and differentiation of keratinocytes (46). Recent studies have shown that IL-22 is expressed by Th17 cells and that both IL-22 and IL-17 can induce anti-microbial peptides commonly seen in psoriatic skin during in vitro stimulation of primary keratinocytes (44). Also, IL-22 levels in plasma correlated with disease severity, and IL-22 in psoriatic skin was associated with increased expression of anti-microbial peptides and matrix metalloproteinases (MMPs) (47). Both in vitro derived, IL-23-differentiated Th17 cells and T cells derived from lesional skin of patients with psoriasis induced expression of anti-microbial peptides by normal human epithelial keratinocytes, which was dependent on IL-17 (20). IL-23 and IL-6, two cytokines that play a role in Th17 differentiation, also upregulate IL-22 production by Th17 cells $(42,44)$. IL-17 has been found to induce IL- 6 production by human keratinocytes and thus may initiate a positive feedback loop resulting in amplification of both IL-17 and IL-22 responses in skin (67).

Recent studies have shown that human Th17 cells express the chemokine receptor CCR6 as well as the CCR6 ligand CCL20 (20, 43). This observation is important, because peripheral blood mononuclear cells (PBMCs) from patients with psoriasis have increased mRNA for CCR6 and skin homing $\mathrm{CLA}^{+} \mathrm{T}$ cells express high levels of CCR6. In addition, lymphocytes from psoriasis patients respond to very low levels of CCL20 and have a greater chemotactic response than those from healthy controls (68). CCR6 and CCL20 are also markedly upregulated in psoriatic skin lesions. Furthermore, TNF- $\alpha$, IL-1 $\beta$, CD40L, IFN- $\gamma$, and IL-17 can induce CCL20 expression in cultures of primary keratinocytes, dermal fibroblasts, dermal microvascular endothelial cells, and DCs (68).

The most compelling evidence for the role of Th17 cells in psoriasis comes from clinical studies. Recent work found that targeting the shared IL-12/IL-23 p40 subunit is an effective treatment for psoriasis. A phase II study of 320 patients with moderate-to-severe plaque psoriasis found that the improvement in psoriasis area-and-severity index (PASI) increased in a dose-dependent manner. At the highest dose,
$81 \%$ of patients had at least $75 \%$ improvement and $52 \%$ of patients had at least 90\% improvement, as compared with $2 \%$ of those who received placebo (69). The improvement was associated with a decrease in the mRNA levels of several proinflammatory cytokines, including the p19 subunit of IL-23 (70). The frequency of serious adverse events was slightly higher in the treatment group versus controls but not statistically significant. Larger studies are still needed to determine if serious adverse events might limit the clinical usefulness, but the results are promising. Treatments that inhibit TNF- $\alpha$ are widely used in RA and are also effective in psoriasis, with significant improvements in PASI, epidermal hyperplasia, and inflammatory infiltrate (71). Interestingly, a recent study found that etanercept (soluble TNF receptor) rapidly downmodulates expression of many Th17-associated cytokines, including IL-17, IL-22, IL-6, IL-1 $\beta$, and IL-23, as well as CCL20 and anti-microbial peptides (71). In contrast, IFN- $\gamma$ and other Th1 effector molecules were not downregulated until very late in disease resolution. This study suggests that Th17 cells are particularly important in driving psoriasis, while Th1 cells may play a minor role in pathogenesis.

RA

Rheumatoid arthritis (RA) is an autoimmune disease characterized by chronic inflammation of synovial tissues in multiple joints associated with bone and cartilage damage (Fig. 1). Until recently, IFN- $\gamma$ was thought to be pathogenic in RA and collagen-induced arthritis (CIA), the prototypical mouse model for RA. IFN- $\gamma$ is expressed in RA serum and synovial fluid, and administration of IFN- $\gamma$ worsens the severity of CIA (72, 73). However, several reports in animal models point to a protective role of IFN- $\gamma$ in arthritis. Mice treated with neutralizing antibodies to IFN- $\gamma$ and IFN- $\gamma$ receptor-deficient mice develop more severe arthritis than wildtype counterparts (74, $75)$, and IFN- $\gamma$ deficiency renders resistant strains of mice susceptible to CIA (76-78). Much like psoriasis, initial studies suggesting that CIA is Th1-mediated have recently been reevaluated with the discovery that the IL-12 p40 subunit is shared by IL-23. Early studies showed that mice deficient in p40 are protected from arthritis, but it is now clear that IL-23, not IL-12, is required for disease. IL-23 p19-deficient mice do not develop CIA, while IL-12 p35-deficient mice actually develop more severe disease (79). Both IL-12 and IFN- $\gamma$ are potent suppressors of Th17 differentiation in vitro, suggesting a potential mechanism for the protective function of these cytokines. IFN- $\gamma$ also regulates endogenous IL-17 responses in vivo in animal models of RA, as arthritic mice deficient in IFN- $\gamma$ or treated with neutralizing antibody to IFN- $\gamma$ have elevated 


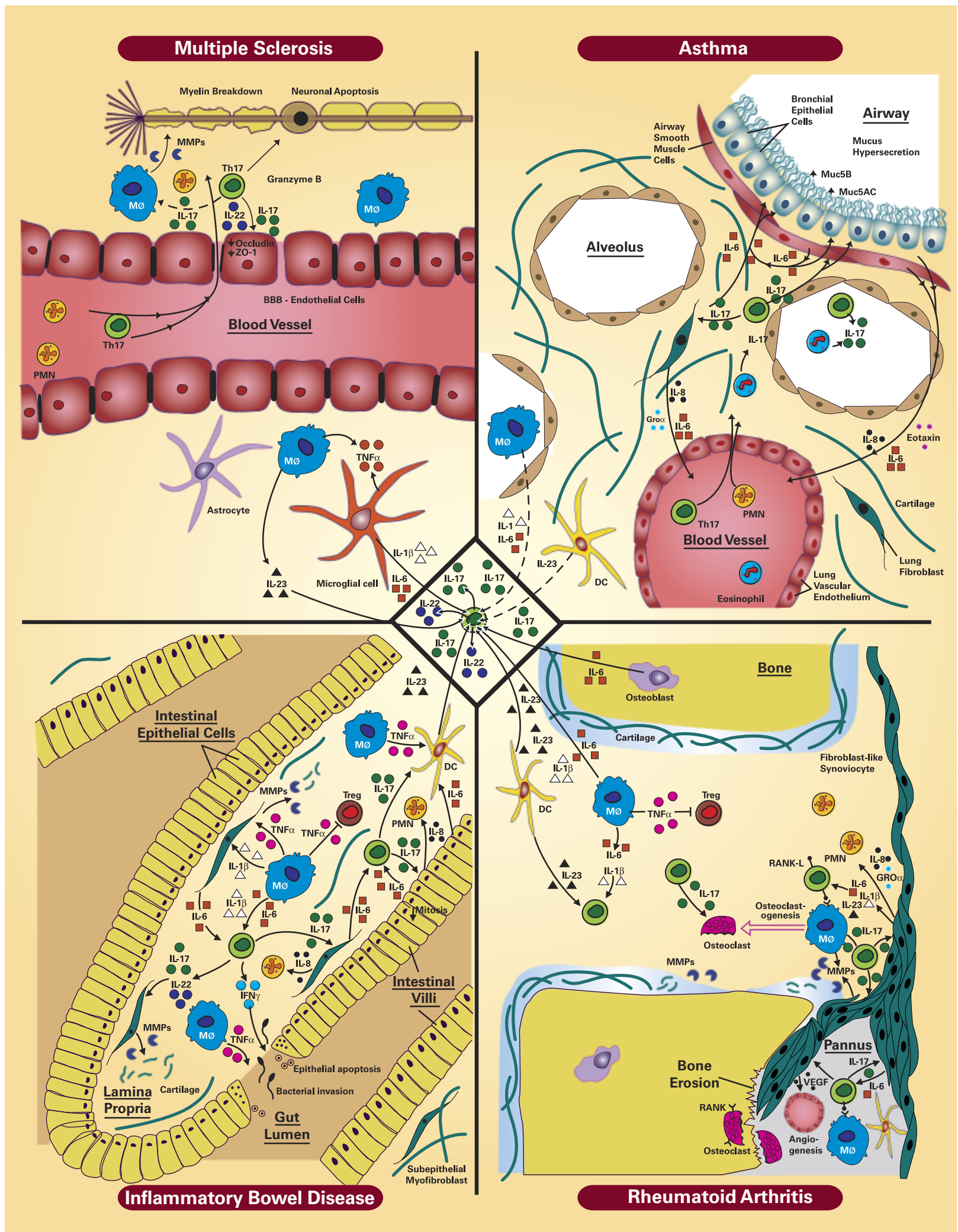

Fig. 1. Th1 7 cells and immune-mediated diseases. Schematic diagram showing the central role played by human Th17 cells in four types of immunemediated inflammatory conditions. The middle diamond represents effects that occur outside the lesions either in lymph nodes or systemically. Solid arrows indicate proven associations, while dashed arrows indicate likely associations based on effects commonly found in other diseases. Shared features include induction of Th17 cells by inflammatory cytokines (IL-1 $\beta$, IL-6, and IL-23) elicited by dendritic cells, macrophages, osteoblasts, or brain microglial cells, either in local lesions or in draining lymph nodes. Common effector functions of Th17-derived IL-17 and IL-22 include induction of chemokines and pro-inflammatory cytokines from stromal cells, and stimulation of matrix metalloproteinases from macrophages and stromal cells. Organ-specific effects such as osteoclastogenesis, disruption of the blood brain barrier, and mucus hypersecretion are described further in the text. 
IL-17 in serum and in cultures of collagen re-stimulated spleens and lymph nodes (76, 80, S. Sarkar et al., manuscript in preparation). Although considerable evidence suggests that IFN- $\gamma$ plays a protective role in CIA by inhibiting Th17 cell development, it may still have pathogenic effects in some instances. For example, the effect of treating CIA with neutralizing antibodies to IFN- $\gamma$ varies depending on the timing of administration, demonstrating that IFN- $\gamma$ may be pathogenic in the early phases of CIA but protective in the later stages (81). In addition, the development of disease in proteoglycaninduced arthritis in the mouse is dependent on IFN- $\gamma$ (82). Similarly, there may be subsets of RA patients with Th1- or Th17-dominant disease.

The importance of IL-17 in the pathogenesis of arthritis in animal models has been shown quite consistently. IL-17 knockout mice develop significantly less arthritis, and treatment with neutralizing antibodies to IL-17 or soluble IL-17 receptor alleviates joint inflammation (83-85). Furthermore, IL-17 receptor signaling in radiation-resistant cells of the joint is required for the induction of chronic destructive synovitis, cartilage damage, bone erosion, and inflammatory cytokine expression in acute streptococcal cell wall arthritis $(86,87)$. IL-17 is also required for the development of spontaneous arthritis in other mouse models of RA, such as IL-1Ra-deficient mice and SKG mice $(88,89)$.

The initial reports of the pathogenic role of IL-17 in RA were from the laboratory of Pierre Miossec (90). His group and others have shown that IL-17 is increased in the sera and synovial fluid of patients with RA and is present in the T-cellrich areas of the synovium (90-92). Importantly, a prospective study in RA patients showed that increased levels of IL-17 and TNF- $\alpha$ mRNA expression in the synovium are predictive of more severe joint damage progression, while high levels of IFN- $\gamma$ mRNA in the joint are predictive of protection from damage progression (93). This evidence clearly points to a role for IL-17 in the pathogenesis of arthritis.

Further support for the role of Th1 7 cells in RA comes from in vitro studies that demonstrate robust and widespread inflammatory effects of IL-17 on cells of the joint. The IL-17 receptor is ubiquitously expressed and initiates an inflammatory response in many cell types important to RA, including monocytes, macrophages, chondrocytes, osteoblasts, and fibroblasts. IL-17 induces the production of inflammatory cytokines such as IL- $1 \beta$, TNF- $\alpha$, IL- 6 , and IL-23 by synovial fibroblasts, monocytes, and macrophages, all of which promote inflammation and Th17 cell development (reviewed in 94). Thus, Th17 cells in the joint may initiate a positive feedback loop, leading to the perpetual T-cell activation that is thought to be critical in the generation of autoimmunity. IL-17 also induces an array of chemokines, including CXCL-1, $-2,-5,-8$, CCL-2, and CCL-20, leading to recruitment of T cells, B cells, monocytes and neutrophils, all of which populate the inflamed joint (reviewed in 94). SDF-1 (CXCL-12), which is present in abundance in rheumatoid synovium and promotes recruitment of $\mathrm{CD}^{+}$memory $\mathrm{T}$ cells, monocytes, and B cells, is induced by IL-17, although IL- $1 \beta$ and TNF- $\alpha$ are not efficient in inducing this factor (95) The leukocyte recruitment is further enhanced by upregulation of granulocyte colony-stimulating factor (G-CSF) and granulocyte-macrophage colony-stimulating factor (GM-CSF), inducers of granulopoiesis, as well as vascular endothelial growth factor (VEGF), an inducer of angiogenesis (reviewed in 94, 96). Clearly, IL-17 can enhance the inflammation and cellular infiltration common in arthritis, but it can also mediate bone and cartilage damage, which cause pain and disability in RA patients. MMPs, nitric oxide, and receptor activator of nuclear factor $\kappa \mathrm{B}$ (RANK)/RANK ligand (RANKL), as well as inflammatory cytokines and chemokines are upregulated in chondrocytes and osteoblasts by IL-17. Th17 cells can induce osteoclastogenesis indirectly by upregulating RANKL and also directly by expressing RANKL on their cell surface (reviewed in 94, 97-99). All the above pro-inflammatory molecules are found in RA synovium and contribute to RA pathology by recruiting and activating inflammatory cells, maintaining the IL-17 response, and causing destruction of tissue and bone.

TNF- $\alpha$ and IL- $1 \beta$ are overexpressed in RA and have a wellestablished role in RA pathology. TNF neutralizing agents are widely used to treat patients with RA with significant efficacy. Several studies have shown that TNF- $\alpha$ and IL-1 $\beta$, either together or separately, can induce the generation of Th1 7 cells $(14,19,34)$, and IL-17 can induce TNF- $\alpha$ and IL-1 $\beta$ expression by synoviocytes as well. The precise mechanisms are still unclear, but IL-23 may be involved in the TNF- $\alpha$ and IL-1 $\beta$-induced secretion of IL-17 $(13,100)$. Such findings provide clues to the mechanism underlying the development of a dysregulated Th17 response in RA. IL-17 can also synergize with TNF- $\alpha$ and IL-1 $\beta$ in mediating inflammation and joint damage, leading some to believe that targeting IL-17 in RA would be redundant with TNF-neutralizing therapies. However, evidence shows that IL-17 can induce inflammation and enhance cartilage and bone erosion in mice, even under TNF and IL-1-neutralizing conditions (101-103). In agreement with this, TNF blockade, along with IL-1 and IL-17 blockade, was more effective at controlling IL-6 production and collagen degradation than blocking TNF alone in cultures of RA synovium (60). Similarly, combination blockade of TNF 
and IL-17 suppressed ongoing CIA and was more effective than neutralization of TNF alone (104). These results suggest that treatments designed to block IL-17 may be beneficial in combination with treatments that block TNF or IL-1, provided that this approach proved to be safe. IL-17-neutralizing therapies may also be particularly useful for the considerable number of patients who do not respond to TNF blockade.

In addition to TNF- $\alpha$ and IL- $1 \beta$, other cytokines involved in Th17 biology can play a role in arthritis, further supporting the idea that Th17 cells are key mediators of joint pathology. In mice, Th17 cells produce IL-21, which acts to further enhance Th17 development. While this pathway has not been examined in human Th17 development, there are several reports which point toward a role for IL-21 in CIA and RA. IL-21 is increased in RA serum and synovial fluid, and its receptor is highly expressed on peripheral blood and synovial fluid lymphocytes, as well as synovial fibroblasts and macrophages from patients with RA $(105,106)$. Administration of IL-21R fusion protein significantly reduced disease in CIA and rat antigen-induced arthritis (107).

IL-23, which enhances IL-17 production and Th17 effector function in humans and mice, is also implicated in arthritis. The role of IL-23 has been shown in CIA, where mice deficient in the IL-23 p19 subunit developed less severe arthritis (79). In RA patients, elevated IL-23 has been found in the sera and synovial fluid, as well as increased expression of IL-23 p19 subunit in synovial fibroblasts $(108,109)$. Recently, STAT4 has been identified as a susceptibility gene for RA $(110,111)$. This is particularly interesting as STAT4, which is important in the signaling pathway through IL-12 and IL-23 receptors, is critical to the generation and maintenance of Th17 cells (30). Consistent with this concept is the finding that STAT4 knockout mice were resistant to arthritis and treatment with anti-sense STAT4 suppressed ongoing CIA (112). It is possible that STAT4 risk alleles would enhance IL-17 responsiveness or provide a continuous endogenous stimulation for the maintenance of the autoimmune Th17 phenotype. Similar to the findings in psoriasis, there is increased expression of IL-22 and IL-22R in the synovium in RA (113), but the effects of this cytokine on cells of the joint are still unknown.

Another cytokine that may play a role in Th17 biology and warrants further investigation is IL-15. There are some indications that this cytokine may be involved in the regulation of IL-17 and autoimmunity. IL-15 is overexpressed in synovial fluid and peripheral blood T cells from RA patients and can induce the secretion of IL-17 from PBMCs (92). Also, RA synovial fibroblasts produce IL-15, which upregulates IL17 and TNF- $\alpha$ production by T cells. IL-17 and TNF- $\alpha$ then, in turn, stimulate production of IL-15 and IL- 6 by the synovial fibroblasts, creating a positive feedback loop (114). In mice, insertion of an IL-15 transgene on an arthritis-resistant strain results in an increased severity of arthritis, associated with increased IL-17 and IL-23 receptor expression (115), while treatment with an IL-15 receptor antagonist ameliorated CIA and downregulated TNF- $\alpha$, IL-1 $\beta$, IL-6, and IL-17 (116).

Our laboratory and several others have begun to characterize the role of $\mathrm{T}$ cell-synovial fibroblast interactions in mediating inflammation and tissue destruction in RA. We have shown that IL-17 can synergize with resting $\mathrm{T}$ cells to stimulate RA synovial fibroblasts to secrete IL-6, IL-8, and prostaglandin $\mathrm{E}_{2}$ $\left(\mathrm{PGE}_{2}\right)$. These interactions were independent of the subset of $\mathrm{T}$ cells and were seen across CD4, CD8, as well as CD45RO and CD45RA subsets (117). We have also shown that synovial fibroblasts readily present superantigens to resting human $\mathrm{T}$ cells, which results in T-cell proliferation and is dependent on surface molecule interactions (118).

Large numbers of $\mathrm{T}$ cells found in the RA synovium are functionally distinct from resting or antigen-activated $\mathrm{T}$ cells and instead resemble $\mathrm{T}$ cells that have been activated solely through exposure to cytokines such as IL-6, IL-2, and TNF- $\alpha$ (119). Studies done in our laboratory have shown that cytokine-activated $\mathrm{T}$ cells can adhere to RA synovial fibroblasts and induce IL- 6 and IL- 8 production from fibroblasts, which was further enhanced by exogenous IL-17. Neutralization of membrane-anchored TNF- $\alpha$, which is expressed by cytokineactivated T cells and is both upstream and downstream of IL17, inhibited the production of these pro-inflammatory cytokines, which are important in mediating joint inflammation in RA and CIA (120). We have also shown that osteoblasts can present superantigen and induce proliferation in $\mathrm{T}$ cells. The $\mathrm{T}$ cells can then in turn induce IL-6 production by the osteoblasts, an effect which is augmented by IL-17 (121). Such findings provide an understanding of the in situ stimulation of $\mathrm{T}$ cells, in the absence of conventional antigenpresenting cells (APCs), in an autocrine and/or paracrine fashion, thus maintaining the self-perpetuating chronic inflammation seen in RA.

Understanding the regulation of Th17 cells will clearly be important in designing therapeutic options targeting IL-17. IL4 is a potent suppressor of IL-17 both in vitro and in vivo. DCs genetically modified to express IL-4 have been shown to inhibit collagen-specific IL-17 production and reduce the incidence and severity of CIA. The suppression mediated by the modified DCs is robust and not reversed by exogenous IL-23, a potent inducer of IL-17 (122, 123). Similarly, injection of an adenoviral vector expressing IL-4 has been shown to 
ameliorate CIA by downregulating joint IL-17 levels and reducing bone and cartilage damage (124).

There is now considerable evidence for the role of Th17 cells in the pathogenesis of arthritis, and IL-17-targeted therapies for RA are likely to be in use soon. Targeting IL-17 directly with neutralizing antibodies or soluble receptors is a viable therapeutic option, but there are also many other approaches to limiting the Th17 response in hopes of achieving long-term efficacy and safety. The arthritic joint presents a unique microenvironment, whereby autocrine and paracrine positive feedback loops mediated by TNF- $\alpha$, IL-1 $\beta$, IL-6, IL-23, and possibly IL-15 promote Th1 7 development and inflammation. Thus, interrupting one or more of these positive feedback loops may limit inflammation directly as well as inhibit maintenance and activation of Th17 cells in the joint, hopefully without paralyzing normal immune responses.

\section{Other rheumatological disorders}

Systemic sclerosis is a connective tissue disease of unknown etiology characterized by fibrosis of skin, lungs, and gastrointestinal tract. Although little is known about the pathogenesis of systemic sclerosis, $\mathrm{T}$ cells infiltrate the skin and are believed to play a role in fibroblast activation. Serum IL-17 is elevated in these patients, especially in the early stages of the disease, and enhances proliferation of fibroblasts as well as expression of adhesion molecules and pro-inflammatory cytokines such as IL- 6 and IL-1. There is also increased expression of IL-17mRNA in the skin and lung tissues (125). It has recently been suggested that IL-21 is involved in the generation of Th17 cells in mice (34), and studies have shown that IL-21R expression is increased in keratinocytes from patients with systemic sclerosis (126).

Systemic lupus erythematosus (SLE) is a chronic systemic autoimmune disease characterized by autoantibodies to nuclear antigens, resulting in inflammation and damage to multiple organs. Type I IFN plays a central role in the pathogenesis of SLE (127), and it has been shown that type I IFN can suppress IL-17 and IFN- $\gamma$ production from human PBMCs (128). This finding makes it unlikely that IL-17 is significant to the pathogenesis of lupus, although IL-17 is elevated in the serum of patients with SLE (129), and contraction of Th17 cells has been associated with improvement in renal disease in mouse models of SLE using tolerizing peptide (130). Recently, polymorphisms in STAT4 have been associated with increased risk for RA, but an even stronger association was seen in patients with SLE (111). The significance of this finding in SLE is not clear at this time, and further understanding of T-cell cytokine biology in these patients is required.

Reactive arthritis (ReA)/undifferentiated spondyloarthropathy (uSpA) is an inflammatory joint disorder that is typically triggered by infection. ReA/uSpA is often a self-limiting disease, but $20 \%$ of patients with ReA develop chronic arthritis. Data on relative cytokine concentrations in ReA/ uSpA are limited and contradictory, with some evidence for a predominance of Th1 cytokines and some evidence for a predominance of immunosuppressive cytokines. However, a recent report found that IL-17, IL-6, TGF- $\beta$, and IFN- $\gamma$ are all elevated in ReA/uSpA synovial fluid as compared with RA, suggesting that both Th1 and Th17 cells may play a role in pathogenesis (131).

\section{ThI 7 cells in non-rheumatic autoimmunity}

MS

Pro-inflammatory cytokines have long been suspected in the induction and pathogenesis of MS (Fig. 1) (132). Most of these early studies found that expression of IL- 6 , IFN- $\gamma$, TNF- $\alpha$, and IL- $1 \beta$, primarily attributed to monocytes, microglial cells, and astrocytes, was correlated with active MS (133-135). Not until 1999 was the presence of elevated levels of mRNA for IL-17 detected in the blood and cerebrospinal fluid (CSF) of MS patients (136). We now know that the development of human Th1 7 cells is dependent on IL- $1 \beta$ and IL-6, thus supporting a role for glial cells and brain-infiltrating monocytes/macrophages in driving the pathogenic T-cell response in MS. Despite the demonstration of elevated IL-17 in serum and CSF of MS patients, very few experiments have been performed to analyze the functional importance of IL-17 in human demyelinating disease. However, several studies using the experimental autoimmune encephalomyelitis (EAE) model in mice have suggested that IL-17 may be a critical pathogenic factor in MS.

Like many other autoimmune diseases, EAE was previously thought to be a Th1-cell-mediated disease. However, immunization of IL-12 receptor- $\beta 2$-deficient mice with the encephalitogenic peptide of myelin oligodendrocyte (MOG) protein resulted in more rapid development of paralysis and increased inflammation of the central nervous system (137). Elevated levels of IL-23 p19 mRNA expression were detected in splenocytes of MOG-immunized IL-12 receptor-deficient mice, and antigen-restimulated splenocytes of knockout mice produced more IL-17 and TNF- $\alpha$ while producing less IFN- $\gamma$ (137). In a reciprocal study, utilizing IL-23p19-deficient mice, EAE induction was completely abrogated despite a similar influx of immune cells into the CNS compared with wildtype mice that developed EAE (8). The CNS-infiltrating $\mathrm{CD}^{+}{ }^{+} \mathrm{T}$ cells 
in IL-23p19 $19^{-/-}$mice expressed IFN- $\gamma$ at levels comparable with wildtype mice, but they completely lacked expression of IL-17, TNF- $\alpha$ and IL- 6 when restimulated with MOG peptide in vitro (8). The production of IL-17 by encephalitogenic antigenactivated $\mathrm{CD} 4^{+} \mathrm{T}$ cells was enhanced by addition of IL-23 to cell cultures, and these Th17 cells were sufficient to induce EAE upon adoptive transfer into a susceptible strain of mice (8).

Spontaneous IL-23 expression was significantly elevated in human monocyte-derived DC (mDCs) isolated from the peripheral blood of MS patients compared with healthy control subjects (138). While transfection with anti-sense IL23 oligonucleotides did not affect major histocompatibility complex (MHC) class II or costimulatory molecule expression on mDCs, supernatants of such mDCs contained lower amounts of IL-23 and were ineffective at inducing IL-17 from purified human $\mathrm{CD}^{+}{ }^{+}$cells compared with supernatants from control mDCs (138). The ability of mDCs from MS patients to stimulate Th17 cells was enhanced by prior bacterial lipopolysaccharide (LPS) treatment of the $\mathrm{mDCs}$, and, in a separate study, mDCs isolated from MS patients with an active bacterial infection were more potent stimulators of IL-17 and IFN- $\gamma$ than mDCs from non-infected MS patients or patients with bacterial meningitis $(138,139)$. The role of mDCs in the induction of Th17 cells reactive to myelin antigens was further substantiated in the mouse EAE model (140). In mice immunized with encephalitogenic antigens, administration of an anti-IL-23 neutralizing antibody delayed and diminished the onset of disease while also decreasing the severity of EAE (141). This therapeutic effect of anti-IL-23 antibody was more profound than treatment with anti-IL-17 antibodies, possibly due to differential effects on the influx of IFN- $\gamma$ and TNF- $\alpha$-producing $\mathrm{CD}^{+}{ }^{+} \mathrm{T}$ cells into the CNS, suppression of epitope spreading, or effects of anti-IL-23 on production of other Th17 cytokines (141). Thus, inhibition of Th17 cell activity by means of IL-23 neutralization may be an effective strategy for treating MS. Another potential treatment strategy in MS could involve the in vivo induction or administration of IL27 , a natural inhibitor of the generation of Th17 cells in mice, but the role of IL-27 in regulating human Th17 cells needs further examination $(142,143)$.

The functional properties of IL-17 in the neuropathology of MS are just beginning to be elucidated. A comparison of Asian patients with opticospinal MS versus conventional MS and control subjects showed increased levels of IL-17 and IL-8 in the CSF of the patients with the more severe, opticospinal form of the disease (144). Levels of IL-17 and IL-8 correlated with the extent of spinal cord inflammation measured by magnetic resonance imaging and the leakage of albumin into the CSF
(144). Autopsied spinal cord tissue showed a remarkable influx of neutrophils and severe damage to myelin and axons at the cornu laterale of the thoracic spinal cord (144). A recent study showed that human $\mathrm{CD} 4^{+} \mathrm{T}$ cells differentiated toward a Th17 phenotype could more effectively traverse through a layer of blood brain barrier endothelial cells (BBB-EC) than their Th1differentiated counterparts (145). These human Th17polarized cells expressed either IL-17 (23.2\% of total $\mathrm{CD}^{+}{ }^{+} \mathrm{CD} 45 \mathrm{RO}^{+}$cells), IL-22 (7.3\%), or both $(17.5 \%)$, and the $\mathrm{IL}-17^{+} \mathrm{IL}-22^{+}$cells preferentially expressed granzyme B and killed neuronal cells isolated from the CNS of human fetuses (145). Cultured human BBB-EC, as well as endothelium in biopsied CNS material from MS patients, expressed IL-17 and IL-22 receptors (145). Human BBB-EC expressed lower levels of the tight junction proteins Occludin and ZO-1 following culture with recombinant human IL-17 but not IL22 , yet both IL-17 and IL-22 pretreatment of a monolayer of BBB-EC enhanced the transmigration of freshly isolated human peripheral blood $\mathrm{CD}^{+}{ }^{+} \mathrm{T}$ lymphocytes (145). Taken together, these data suggest that one role of Th17 cells in MS is to weaken the $\mathrm{BBB}$, allowing the influx of serum albumin, $\mathrm{CD} 4^{+}$ T lymphocytes, and neutrophils, attracted by elevated IL-8 in the CSF. In diseases such as RA, IL-17 is recognized as a stimulator of MMP expression, and there is a strong association between MMPs, BBB dysfunction, and neuronal apoptosis in MS $(146,147)$. However, no direct role of IL-17 on the expression of MMPs in the brain or spinal cord has been established. Much further work is needed to characterize these and other effects of IL-17 and IL-22 on human brain endothelial cells, astrocytes, and microglial cells in MS.

\section{Other autoimmune diseases}

Autoimmune myocarditis is generally attributed to an immune reaction toward cardiac myosin following heart infections and is the leading cause of heart failure in young adults (148). Findings that mice lacking the Th1-associated transcription factor T-bet were more susceptible than wildtype mice to experimental autoimmune myocarditis led to the discovery that these mice had elevated IL-23 and IL-17 production (149). Experimental myocarditis was reduced by in vivo neutralization of IL-17 $(149,150)$. Very recently, it was shown that IL-17 stimulated primary human cardiac fibroblasts to express MMP1, MMP-2, MMP-9, and MMP-13, suggesting that IL-17 may play a significant role in fibroblast migration into the inflamed heart and cartilage breakdown (151).

Endometriosis results from the growth of uterine glandular epithelial cells and stromal cells in the peritoneal cavity and is often considered an autoimmune phenomenon based on the 
production of autoantibodies (152). The production of antilaminin antibodies in association with endometriosis is a significant risk factor for infertility and miscarriages within the first trimester of pregnancy (153). A study of 62 women undergoing laparoscopic surgery for infertility, abdominal pain, pelvic mass, or tubal sterilization revealed that 36 women had evidence of endometriosis, and among these, the women with infertility $(\mathrm{n}=17)$ had significantly elevated IL-17 levels in their peritoneal fluid compared to women without endometriosis or women with endometriosis without infertility (154).

Vogt-Koyanagi-Harada (VKH) disease is an autoimmune disease associated with immune attack of melanocytes resulting in diffuse granulomatous panuveitis and systemic manifestations including alopecia, vitiligo, poliosis, and central nervous system disorders (155). IL-23 was elevated in the serum of VKH patients that had active uveitis compared with healthy controls, whereas no elevation in IL-23 was detected in VKH patients without active uveitis (156). Similarly, peripheral blood $\mathrm{CD}^{+}{ }^{+} \mathrm{T}$ cells from VKH patients with active uveitis produced higher levels of IL-17 when stimulated with anti-CD3 and anti-CD28 antibodies than $\mathrm{T}$ cells from healthy controls or VKH patients without uveitis (156). Experimental autoimmune uveitis elicited by immunization of mice with interphotoreceptor retinoidbinding protein resulted in the production of antigen-specific $\mathrm{CD}^{+}{ }^{+} \mathrm{T}$ cells producing IL-17 that were capable of transferring disease (157). In humans with non-VKH uveitis, Th17 cells were found in the peripheral blood at levels directly correlating to disease activity (25). Interestingly, these human Th17 cells from uveitis patients were expanded in the presence of human IL-2 and inhibited by IFN- $\gamma(25)$.

Despite established associations between the autoimmune endocrine diseases, such as type I diabetes and autoimmune thyroiditis, and Th17-associated cytokines IL-1 $\beta$, IL-6, and TNF- $\alpha$, there has been relatively little attention given to the role played by Th17 cells in endocrine autoimmunity (158-160). In a subdiabetogenic model of type I diabetes in mice, daily injections of IL-23 led to increases in pancreatic IL-17, IFN- $\gamma$, TNF- $\alpha$, and IL-18 that correlated with increased cellular infiltration, islet apoptosis, and hyperglycemia (161). Polymorphisms in the genes for IL- $1 \beta$, IL-1RA, IL-6, and TNF- $\alpha$ were studied in cohorts of Hashimoto's thyroiditis patients and healthy controls, and among these, only the polymorphism C/G in the IL-6 promoter region $(-572)$ was shown to be statistically significant in thyroiditis patients. One study has demonstrated that blockade of TNF- $\alpha$ in granulomatous experimental autoimmune thyroiditis resulted in the resolution of chronic lesions that was coincident with a decrease in IL-17 and other pro-inflammatory cytokines (162). While suggestive that Th 17 cells may also play a role in diabetes and thyroiditis, these studies need to be followed-up with wellcontrolled human studies before advancing the idea that endocrine autoimmunity is Th17 mediated (163).

\section{ThI 7 cells in asthma and allergic diseases}

Asthma

The above correlations between the presence of IL-17A and cell-mediated autoimmune diseases that were traditionally thought to be Th1 dependent might lead one to conclude that IL-17 is not involved in Th2-mediated inflammation. However, there is significant evidence that suggests an important role for IL-17 in the pathogenesis of allergies and asthma (Fig. 1). Sputum samples from asthmatic patients have been shown by several independent groups (164-166) to contain elevated levels of IL-17 compared with control subjects. Patients with allergic asthma also had elevated levels of IL-17 in plasma compared with non-asthmatic control subjects (167), although this study did not have enough participants to reach statistical significance. More direct evidence that Th17 cells contribute to allergic asthma in humans comes from a study of Dermatophagoides farinae (Df)-restimulated T-cell clones from the peripheral blood of atopic asthmatic patients (168). Although mitogenic stimulation of PBMCs using anti-CD3 and antiCD28 antibodies induced equivalent levels of IL-17 from control subjects, non-atopic asthmatics, and allergic asthmatics, only the asthmatic patients produced IL-17 following Df-mediated activation (168).

IL-17 is thought to have several functions in the lung, as well as systemically, to promote allergic asthma. Human bronchial fibroblast cells respond to stimulation with IL-17 in vitro by producing IL- 6 , IL- 8 , and GRO- $\alpha$ (164). IL- 8 and GRO- $\alpha$ are known chemoattractants for neutrophils, and IL-6 is a neutrophil-activating cytokine (169). Thus, the increased expression of IL-17 in the lung during asthma may explain the increased accumulation and activation of lung neutrophils. Similarly, cultured human airway smooth muscle cells produced IL- 8 and IL- 6 upon activation with IL-17, and the production was enhanced by IL- $1 \beta$ and TNF- $\alpha$, respectively $(170,171)$. Similarly, eotaxin-1 (CCL11) was produced by human airway smooth muscle cells cultured with IL-17, an effect that was cooperative with induction by IL-1 $\beta$ (172). Cooperative effects between IL-17 and TNF- $\alpha$ were also detected in the stimulation of IL- 8 and IL- 6 production by human lung epithelial cells (173). In addition to its local and systemic effects on neutrophils, IL-17, acting through 
stimulation of IL-6, was also shown to induce the expression of the mucin genes, MUC5B and MUC5AC, by human bronchial epithelial cells (174). Surprisingly, the Th2 cytokines IL-4, IL9, and IL-13 did not have the same effect on human bronchial epithelial cells (174).

The production of IL-17 is primarily attributed to $\mathrm{CD}^{+}{ }^{+} \mathrm{T}$ cells, and T-cell clones derived from PBMCs of atopic asthma patients produced IL-17 upon restimulation with Df extract (168). Interestingly, the production of IL-17 was not restricted to $\mathrm{CD}^{+}{ }^{+}$Th cells in the sputum and bronchial alveolar lavage (BAL) of asthmatic patients, but IL-17 was also detected in airway eosinophils by immunocytochemistry (164).

The accumulated evidence suggests that IL-17 plays an important pathologic role in the development of allergies and asthma. This presents the possibility that interfering with the activity of Th17 cells or IL-17 could be an effective treatment modality (175). In vitro studies have shown that glucocorticoids can interfere with the induction of cytokines and chemokines by human bronchial fibroblasts and epithelial cells $(164,169)$, and one study demonstrated that oral corticosteroid treatment reduced the levels of IL-17 detected by immunocytochemistry in bronchial biopsy specimens (176).

\section{Atopic dermatitis and contact hypersensitivity}

In addition to the role played by Th1 7 cells in allergic asthma and psoriasis, emerging evidence suggests that IL-17-producing $\mathrm{T}$ cells are also involved in the pathogenesis of atopic dermatitis and contact hypersensitivity $(177,178)$. As is the case with most autoimmune diseases and asthma, the incidence of atopic dermatitis, a chronic inflammatory disease of the skin, is increasing in developed countries (179). Genetic as well as environmental factors are thought to be critical to disease etiology and atopic dermatitis, which usually begins during childhood, often precedes development of atopic rhinitis and asthma in susceptible individuals (179). Immunohistochemical analysis of acute and chronic lesions from atopic dermatitis patients revealed that IL-17 was preferentially associated with acute atopic dermatitis but not the chronic skin specimens (180). The cellular source of IL-17 in atopic dermatitis skin lesions was not evaluated.

Contact hypersensitivity is an allergen-induced skin inflammatory reaction mediated by $\mathrm{CD}^{+} \mathrm{T}$ cells that was traditionally associated with IFN- $\gamma$-producing Tc1 cells. However, neutralization of IL-17 was effective at suppressing contact hypersensitivity in DNFB-treated mice while blockade of IFN- $\gamma$ was ineffective (181). Interestingly, $\mathrm{CD}^{+} \mathrm{T}$ cells were the main producers of IL-17 in this model system, and blockade of IL-17 led to decreased levels of IL-1 $\alpha$, IL-1 $\beta$, IL-6, and IFN- $\gamma$ in the sensitized ear tissue (181). Blockade of the voltage-gated potassium channel, Kv1.3, which has been shown to be expressed by effector-memory $\mathrm{T}$ cells in autoimmunity, inhibited hapten-induced allergic contact dermatitis in a rat model $(182,183)$. The inhibition of allergic contact dermatitis correlated with decreased infiltration of the skin by $\mathrm{CD} 8^{+} \mathrm{T}$ cells and reduced levels of IL-17, IL-2, and IFN- $\gamma$ (183). Studies in human skin inflammation are limited, but it was demonstrated that nickelelicited human $\mathrm{CD}^{+}{ }^{+} \mathrm{T}$ cells simultaneously produced IL-17, IFN- $\gamma$, and TNF- $\alpha$ (184). Recombinant IL-17 induced production of IL-8 from human keratinocytes, both directly and synergistically with IFN- $\gamma$ and TNF- $\alpha$ (184). Thus, IL-17 production seems to be a common feature in skin inflammation not only in psoriasis patients but also when induced by allergens. It will be interesting to determine if treatment of atopic dermatitis and contact hypersensitivity by corticosteroids or the topical calcineurin inhibitors, tacrolimus ointment, or pimecrolimus cream, result in decreased IL-17 production by skin-infiltrating $\mathrm{CD}^{+}{ }^{+}$and $\mathrm{CD} 8^{+}$T cells (179).

\section{Th 17 cells in other immune-mediated diseases}

IBD

As in other inflammatory diseases that attack self-tissues, IL-23 and Th17 cells are emerging as the prime targets for disease intervention in the inflammatory bowel disease (IBD), specifically Crohn's disease and ulcerative colitis (185) (Fig. 1). Several studies in both spontaneous and bacteria-induced mouse models of IBD have established that IL-23, but not IL12, is an essential cytokine for intestinal inflammation (22, $186,187)$. These data in mice shed new light on the mechanism of clinical remission of Crohn's disease mediated by antibodies against the p40 subunit shared by IL-12 and IL-23 (188). A recent large cohort study in European populations of differing ethnicities described a single nucleotide polymorphism in the IL-23 receptor (Arg381Gln) that is significantly associated with both Crohn's disease and ulcerative colitis (189). New orally administered drugs that inhibit both IL-23 and IL-12 are currently being tested for clinical efficacy against Crohn's disease in Phase I and II trials with promising results thus far $(190,191)$.

Although still under intense investigation in humans, mouse Th17 cells do not require IL-23 for early commitment to the Th17 lineage, but rather utilize IL-23 to sustain IL-17 production and promote effector function (21). Early human Th17 development is currently believed to rely on the inflammatory cytokines IL-1 $\beta$ and IL-6 $(19,20)$. Human IL$1 \beta$ and IL-6 have long been identified as mediators of intestinal 
inflammation, their production along with TNF- $\alpha$ being mainly attributed to activated monocytes/macrophages in the gut lamina propria (192-194). Isolated peripheral blood and gut $\mathrm{CD}^{+}{ }^{+} \mathrm{T}$ cells from Crohn's disease patients made IL-17 upon stimulation with phorbol myristate acetate and ionomycin in vitro, with almost $40 \%$ of the IL-17-producing T cells in the gut also expressing IFN- $\gamma$ (17). Biopsies of inflamed colonic tissue from patients with either Crohn's disease or ulcerative colitis expressed IL-17 at the mRNA level and CD4 ${ }^{+}$Th17 cells were found clustered in the lamina propria (195). In a separate study, $\mathrm{CCR}^{+}{ }^{+} \mathrm{T}_{\text {cells }}$ isolated from the lamina propria of Crohn's disease patients produced high levels of IL-17 when restimulated in vitro, but $\mathrm{CCR}^{+} \mathrm{T}$ cells from healthy individuals did not produce IL-17 (196). IL-22, a putative product of human Th17 cells, was also found to be overexpressed by colonic $\mathrm{CD}^{+}{ }^{+} \mathrm{T}$ cells in patients with IBD compared with healthy controls (48). Thus, the intestinal lamina propria appears to be an inductive site for human Th17 cells during IBD.

The effector functions of IL-17 and IL-22 in the inflamed human intestine are just beginning to be studied. IL-17A induced the expression of G-CSF from human peritoneal mesothelial cells, a mechanism that promotes the accumulation of polymorphonuclear neutrophils in the peritoneum (197). The G-CSF-inducing effect of IL-17A on mesothelial cells was synergistic with TNF- $\alpha$ and was mediated through activation of NFKB (197). IL-17A and IL-17F, but not other IL-17 family members, have been shown to stimulate MMP production and the release of pro-inflammatory cytokines, such as IL-6, IL-8, and leukemia inhibitory factor (LIF), from cultured primary human colonic subepithelial myofibroblasts (SEMF) (198). Optimal induction of inflammatory mediators was only achieved at concentrations of IL-17A and IL-17F above $500 \mathrm{ng} / \mathrm{ml}$, suggesting that intimate contact between Th17 cells and SEMF might be required for these effects in vivo (198). The levels of cytokines and MMPs induced by IL-17A and IL-17F (500 ng/ml) alone were several fold lower than those induced by either IL-1 $\beta$ $(10 \mathrm{ng} / \mathrm{ml})$ or TNF- $\alpha(100 \mathrm{ng} / \mathrm{ml})$, but both IL-17 family members acted cooperatively with IL-1 $\beta$ and TNF- $\alpha$ to enhance IL-6, IL-8, MMP-1, and MMP-3 expression in SEMF cells (198). Very similar results were obtained when IL-22 was used to stimulate primary human SEMF (48). In addition to the above-listed MMPs and inflammatory cytokines, IL-22 was shown to induce IL-11, MMP-10, and several neutrophilattracting chemokines (48). IL-22 was also found at higher levels than IL-1 7 or IFN- $\gamma$ in the serum of patients with Crohn's disease and induced secretion of LPS-binding protein from cultured human hepatocytes, a mechanism that may protect
Crohn's disease patients from LPS-mediated systemic inflammation (199). IL-17 also inhibited the proliferation of cultured human intestinal epithelial cells, an important repair mechanism needed to maintain epithelial integrity (200). In the same study, the combination of TNF- $\alpha$ and IFN- $\gamma$ potently induced intestinal epithelial cell apoptosis, while IL-17 had no effect on cell death (200). Yet the combination of IL-17, TNF- $\alpha$ and IFN- $\gamma$, the latter being co-produced by Th17 cells in the intestine, would be expected to elicit damage to the epithelial barrier that would not be repaired by epithelial cell proliferation.

Taken together, these findings suggest that Th17 cells and the inflammatory mediators that either induce them (IL-1 $\beta$, IL-6, and IL-23), act in concert with IL-17 (TNF- $\alpha$ and IL-1 $\beta$ ), or work downstream of IL-17 to mediate gut inflammation (GCSF, chemokines, and MMPs) are all attractive targets for treatment of IBD. Treatment with TNF blockers, IL-23 inhibitors, IL-1 receptor antagonist, or anti-IL-6 may soon become the standard of care for IBD patients (190, 191, 201, 202). Interestingly, other emerging treatments that have shown clinical efficacy, such as apheresis and dietary modifications, have resulted in reduced mucosal concentrations of IL- $1 \beta$, IL6 , and IL-8 suggesting possible effects on human mucosal Th1 7 cell development and function $(203,204)$.

\section{Periodontal disease}

Periodontitis and gingivitis are initiated by Gram-negative bacterial infections in the mouth and are mediated, in part, by activation of $\mathrm{CD}^{+}$and $\mathrm{CD}^{+} \mathrm{T}$ cells (205). Significant parallels between the disease pathogenesis of periodontitis and RA suggested that IL-17 might be a key contributor to periodontal disease $(205,206)$. Stimulation of PBMCs collected from patients with gingivitis and periodontitis by the outer membrane protein (OMP) of Porphyromonas gingivalis, a causative microorganism in periodontal disease, led to OMPinduced expression of IL-17 (207). Comparison of IL-17 mRNA expression from freshly excised gingival tissue and peripheral blood of the same patients revealed that, in the majority of cases, IL-17 expression was much higher in gingival tissue (207). Subsequent studies have confirmed the presence of IL-17 in inflamed gingival tissues (208-210), and one report showed that levels of IL-17 were high at an intermediate stage of disease progression and then returned to baseline levels in patients with more severe lesions (208). In contrast, peak levels of IL-11 were reached earlier in disease than IL-17, whereas levels of IL-6 and RANTES were highest in severe disease (208). However, a recent follow-up study by the same group showed that levels of IL-17, IL-23, IL-1 $\beta$, IL-6, and 
TNF- $\alpha$ were highest in the most severe sites of inflammation, but this difference may be attributable to a change in the definition of severity (211). In a separate study, immunocytochemistry revealed that the frequencies of cells staining positive for IL-1 $\beta$, TNF- $\alpha$, and IL-17 were 5.0-, 3.9-, and 6.2-fold higher in gingival tissue from periodontitis patients than in healthy controls (212).

Culture supernatants of unstimulated gingival tissue and T-cell lines derived from gingiva of periodontitis patients were positive for IL-17 protein and mRNA, respectively $(210,213)$. Similar to the findings in inflamed gingival tissues, IL-17 was found in the deeper, surgically removed, periapical lesions of patients that showed signs of periapical alveolar bone loss by radiography (214). IL-17 levels in the periapical tissue directly correlated with levels of IL-8, and IL-17 stimulation of mononuclear cells from peripheral blood and periapical lesions of symptomatic patients resulted in dose-dependent increases in IL-8 production by mononuclear cells (214).

The role of IL-17 in mediating periodontal disease seems to parallel the roles attributed to IL-17 in RA and other diseases. Human gingival fibroblasts were stimulated to secrete IL-6 upon activation with recombinant IL-17, an effect that was neutralized by addition of anti-IL-17 antibody $(209,212)$. IL17 also directly induced gingival fibroblasts to produce IL-8 and modest amounts of proMMP-1 and MMP-3, as well as inducing IL- $1 \beta$ and TNF- $\alpha$ production from healthy, adherent, PBMCs (212). IL-1 $\beta$ and TNF- $\alpha$ were potent stimulators of MMP expression by gingival fibroblasts, thus IL-17 may have direct and indirect roles in the production of MMPs in periodontal disease (212).

These findings suggest that blockade of the IL-17 axis could be a potential treatment option in periodontal disease. However, strong caution is warranted in this disease setting, because IL-17 has known important functions in the control of Gram-negative bacterial infections such as those that cause periodontitis. Proof of the danger involved in blocking IL-17 in the mouth comes from a study of P. gingivalis infection in IL-17 receptor A-deficient mice in which periodontal bone destruction was exacerbated (215).

\section{Th 17 cells in host defense against infection}

Bacteria

Little direct information exists regarding the importance of IL17 and Th17 cells in resistance to infection in humans. Such knowledge is critical, as clinical interventions to regulate or neutralize IL-17 are likely to be tested in the near future. Much more is known in the mouse, which, despite obvious environmental and genetic differences from human, has often been a reliable species to indicate infectious risks attendant upon neutralization of cytokines, for example TNF.

Relevant genetic defects in humans are confined to rare individuals with homozygous mutation of either the IL12B gene, which encodes the p40 subunit common to IL-12 and IL23, or the IL12BR1 gene, which encodes a subunit of the IL-12 and IL-23 receptors (216). Infectious difficulties in these individuals are mainly due to mycobacteria and salmonella, and this occurrence has been attributed to the Th1 deficiency rather than Th17 deficiency. It has therefore been inferred that IL-17 might not have an important role in protection against pathogens (217), which, if true, would be an important advantage for approaches to human autoimmune disease that employ IL-17 inhibition. Considerable caution is warranted, however, in extrapolating observations from IL-23-deficient states to the anticipated consequences of IL-17 blockade, because Th17 cell development is supported by cytokines other than IL-23, and the role of IL-23 in Th17 development and expansion appears to be at least partly redundant. Deficiency of tyrosine kinase 2 (tyk2), which is required for signaling through IL-23R, has been reported to lead to susceptibility to multiple infections in the context of hyperimmunoglobulin E syndrome (218). However, tyk2 is involved in signal transduction by multiple cytokine receptors, including those for IL-12, IFNs, IL-6, and IL-10, as well as IL23, so that effects on Th17 cells are unlikely to underlie all of the immune aberrations in such patients.

In mice, there is considerable evidence that IL-17 and/or IL23 are important in host responses to infection by Gramnegative bacteria, specifically Klebsiella, Pseudomonas, Escherichia coli, Salmonella, and Bordetella species. This role is not solely due to generation of an adaptive Th17 response but also reflects innate immune properties of IL-23 and IL-17. For example, Toll-like receptor 4 (TLR4) triggering by E. coli LPS can lead to rapid release of IL-23, which induces prompt release of IL-17 by $\gamma \delta \mathrm{T}$ cells. IL-17 from $\gamma \delta \mathrm{T}$ cells peaks at $6 \mathrm{~h}$ in locations such as the peritoneal cavity, resulting in a subsequent influx of neutrophils within $24 \mathrm{~h}$ (219). Neutrophil chemotaxis induced by IL-17 is primarily indirect, and IL-17 can induce chemokine production by peritoneal mesothelial cells (220). IL-17 can also induce release of G-CSF, which increases neutrophil production in the bone marrow (221). In leukocyte function-associated antigen-1 (LFA-1) ${ }^{-/-}$mice (a model for a human immunodeficiency), both G-CSF and IL-17 are strikingly elevated compared with $\mathrm{LFA}-1^{+/-}$mice. LFA- ${ }^{-1-}$ mice have neutrophilia and are resistant to intravenous infection with Listeria monocytogenes, due to enhanced neutrophil infiltration of organs such as the liver 
(222). These unexpected results provide an unusual example of resistance to a specific infection as a consequence of an immunodeficiency. The data also indirectly suggest that LFA-1 signaling could exert a negative effect on IL-17 production and that neutrophilia in LFA-1 deficiency is not due solely to ongoing infection.

IL-17 induction of neutrophil chemotaxis is important in defense against a variety of organisms that infect the lung, such as Klebsiella pneumoniae. In mice infected with this organism, TLR4 expression in the lung leads to production of IL-23 by DCs, which then stimulates both $\mathrm{CD} 4{ }^{+}$and $\mathrm{CD} 8{ }^{+}$lymphocytes to release IL-17 (223). Endotoxin alone, when introduced into the respiratory tract, can initiate an IL-17-dependent pathway that leads to neutrophil influx $(224,225)$. When mice are fed ethanol, a risk factor for aggressive pulmonary infection by Klebsiella in humans, release of IL-17 and recruitment of neutrophils in the lung is suppressed, and mortality is enhanced (226). Local gene therapy for IL-17 restores IL-17 production and survival in this system. Likewise, in mice infected with Mycoplasma pneumoniae, infiltration of the lung by neutrophils is dependent upon IL-23-induced upregulation of IL-17A and IL-17F (227).

The important respiratory pathogen Bordetella pertussis, the cause of whooping cough, employs multiple pathways to elicit an IL-17 response. Protection of mice by the pertussis vaccine requires production of IL-23, IL-1, and IL-17, and generation of these cytokines is dependent on TLR4 on APCs. IL-17 then activates macrophage killing of B. pertussis. A Th1 response, along with a Th17 response, may be necessary for optimal immunity to this organism (228). In addition, pertussis toxin enhances Th17 differentiation while suppressing Treg generation or function, through induction of IL-6 production (229).

Another very important respiratory pathogen in humans is Streptococcus pneumoniae, and antibody responses to capsular polysaccharides are believed to be critical in host defense against natural infection, as well as in the protective immunity induced by the pneumococcal vaccine. In a mouse model of intra-nasal pneumococcal vaccination, protective immunity could be induced in agammaglobulinemic animals in an IL17-dependent manner (230). These results imply that at least some Th17 cells recognize carbohydrate antigens. Consistent with this concept, IL-17 was required for formation of intraabdominal abscesses in response to Bacteroides fragilis or polymicrobial cecal contents, a process dependent upon recognition of bacterial polysaccharides by $\mathrm{CD}^{+} \mathrm{T}$ cells. Abscess formation required T-cell costimulation by the CD28B7 pathway and was compromised in STAT4 ${ }^{-1-}$ animals (231,
232). Survival in the face of intra-abdominal sepsis can potentially be enhanced by concurrent triggering of TLR9 by $\mathrm{CpG}$ oligodeoxynucleotides, and in a rat model, this effect was found to be dependent upon IL-17 and probably IL-23 (233).

A variety of microbial products can thus lead to IL-17 production through both TLR-dependent and TLRindependent pathways (234). Relevant TLR pathways include those initiated by TLR4 and TLR9. The effects of TLR9 agonists in promoting IL-17 and IFN- $\gamma$ production can be antagonized by type I IFNs (128). The effects of TLR2 ligation on IL-17 production are more uncertain at this point. On one hand, TLR2 ligands from a non-pathogenic bacterium robustly stimulated IL-23 production (235). However, in a mouse model of brain abscess due to Staphylococcus aureus, TLR2 knockout mice manifested increased IL-17 in the brain, without effect on outcome or survival (236). Recently human DCs were shown to use the intracellular NOD-2 receptor to recognize the muramyldipeptide component of bacterial peptidoglycan and respond by producing IL-23 and IL-1, that in turn stimulated Th17 cell development (237). In the effector phase of host defenses, the Th17 cytokines IL-17 and IL-22 can stimulate tissue cells to produce a variety of anti-microbial peptides (44).

In some circumstances, IL-23 and/or IL-17 may even be associated with an unfavorable outcome of infection. For example, neutralization of IL-23 promoted survival in a mouse model of endotoxic shock induced by Pseudomonas aeruginosa (238). These results, considered in context of the multiple pro-inflammatory effects of IL-17 and IL-23 in the lung (239), raise questions about a potential harmful role of IL-23 and IL-17 in patients with cystic fibrosis, whose lungs are frequently infected by Pseudomonas, an organism that is associated with an adverse clinical course in this disease. Indeed, IL-17 and IL-23 levels are elevated in the sputum of patients with cystic fibrosis who are infected with Pseudomonas (240). In mice challenged with this organism, IL-23p19 ${ }^{-1-}$ animals had less pulmonary inflammation without an increase in bacterial dissemination, leading the authors to suggest consideration of therapeutic neutralization of IL-23 in cystic fibrosis. The IL-17 response in Helicobacter pylori infection might also contribute to deleterious inflammation of the stomach due to induction of chemokines (241).

The role of IL-17 in the arthritis of Lyme disease, which is caused by the spirochete Borrelia burgdorferi, illustrates the complex effects of pro-inflammatory cytokines in syndromes at the junction of infection and immune-mediated disease. An early report that B. burgdorferi lipopeptides induced IL-17 
production by $\mathrm{T}$ cells via effects on APCs included the astute observation that IL-17 could not be classified as either a Th1 or a Th2 cytokine (242). Subsequently, it was shown that murine APCs preferentially produced IL-23, rather than IL-12, upon exposure to B. burgdorferi. Neutralization of IL-17 was shown to be therapeutic in a murine model of Lyme disease (243), in association with expansion of the Treg $\mathrm{CD} 4{ }^{+} \mathrm{CD} 25^{+}$ population (244). Antigens derived from B. burgdorferi are among a group of LPSs and glycolipids that induce IL-17 from a subset of invariant NKT cells (245). More information is needed about the sources and roles of IL-17 in human Lyme disease.

Such examples of a deleterious role of IL-17 or IL-23 in the outcome of bacterial infection are unusual, however. Although the available data derive primarily from rodent models, exposure of human monocytes to the Gram-negative bacterium Francisella tularensis, the cause of tularemia, upregulated expression of transcripts for the p19 subunit of IL-23 by $300-$ fold and also led to a striking up-regulation of p40 transcripts (246). It therefore should be assumed that the significant body of work that has established a role for IL-17 in host defense against bacteria, especially Gram-negative organisms, has substantial implications for the potential use of IL-17 neutralization in the treatment of human disease, both in the design of clinical trials and in subsequent use in broader populations of patients.

\section{Mycobacteria}

The observation that TNF blockade in the treatment of RA and IBD led to frequent reactivation of tuberculosis highlighted the importance of understanding the role of a cytokine in control of mycobacterial infections before undertaking its therapeutic neutralization. Animal model systems have demonstrated the essential role of TNF in host defense against tuberculosis. In contrast, the role of IL-17 in animal models of tuberculosis is far less clear or convincing. Although IL-23 can fortify lung defenses against Mycobacterium tuberculosis (MTB) (247) and can substitute for IL-12 in such responses (248), its primary role in this setting seems to be the induction of IFN- $\gamma$, with IL-17 production of lesser importance. In the absence of IL-12 or IFN- $\gamma$, the IL-23/IL-17 axis produces a neutrophilic pulmonary infiltrate that is less effective in controlling MTB infection (249). Indeed, upregulation of IL-17R expression is a characteristic of mouse strains that show enhanced susceptibility to MTB, in association with an exaggerated neutrophil influx at the site of infection, whether pulmonary or peritoneal (250). The source of IL-17 in murine MTB infection appears to be primarily from $\gamma \delta \mathrm{T}$ cells and other non-CD $4^{+}$cell populations, and induction of IL-17 by IL-23 occurs as early as 1 day into infection, suggesting an innate rather than adaptive response pathway (251).

In experimental Mycobacterium bovis (BCG) infection, absence of IL-23 does not compromise control of infection and neutralization of IL-17 has little effect, in the presence or absence of IL-12. However, in the absence of IL-12, IL-23 plays an important role as an inducer of a Th1 response (252). Moreover, IFN- $\gamma$ regulates IL-17 production during BCG infection, which could limit deleterious influx of neutrophils (253). It has been reported that in the context of IL-17 deficiency the Th1 response in BCG infection is less robust (254). As with MTB infection, IL-17 appears early, is dependent on IL-23, and is produced by $\gamma \delta \mathrm{T}$ cells instead of $\mathrm{CD}^{+} \mathrm{T}$ cells. Importantly, despite these observations, mycobacterial numbers in various organs are not increased in IL-17 knockout mice (254).

BCG is used as a live vaccine to partially control MTB infection. Alternative strategies for induction of protective immunity to MTB are also being explored. In mice immunized with an MTB DNA vaccine, a protective response was not seen in $\mathrm{p} 40^{-/-}$animals. Partial reconstitution of either IL-12 or IL-23 by gene therapy using transfected APCs was partially protective. In $\mathrm{p}^{-1} 0^{-1}$ mice immunized subcutaneously with BCG and later challenged with MTB, an IL-23-independent induction of an IL-17 response was observed in lymph nodes but not in lung tissue, which correlated with a reduced mycobacterial load in the lung (255). Furthermore, vaccination of mice with a peptide derived from the mycobacterial antigen ESAT-6 (6 kDa early secreted antigenic target protein) induced an accelerated and protective Th1 response that required IL-23 and IL-17. This result was postulated to reflect early influx of Th17 cells into the lung, which engendered production of chemokines that efficiently recruited $\mathrm{CD} 4{ }^{+}$cells, which then mediated a Th1 response (256). However, the ESAT-6 protein, which binds to Toll-like receptor-2 (TLR-2), has also been shown to inactivate other TLR signaling pathways and truncate the innate immune response to mycobacteria (257).

The available data suggest that neutralization of IL-17 would be unlikely to paralyze host defenses against mycobacteria, although more data are needed in models of reactivation of latent infection. However, neutralization of p40, an approach already in use in human immune-mediated diseases, could be problematic because of simultaneous compromise of both Th1 and Th17 immunity. Furthermore, strategies that interfere with IL-17 might perturb the response to mycobacterial vaccines in ways that are currently difficult to anticipate. 
Fungi and other opportunistic pathogens

In a mouse model of infection with the fungal organism Cryptococcus neoformans, the IL-23/IL-17 axis was shown to have a significant role in host defense, although Th1 responses were more important (258). Likewise, a protective role for IL-23 and IL-17 was documented in a mouse model of Pneumocystis carinii lung infection (259). In contrast, the role of IL-17 in host defense against the fungal pathogen Candida albicans is controversial. Mice lacking the IL-17A receptor had reduced survival following intravenous injection of this organism, and gene therapy with IL-17 (IL-17A) enhanced survival of normal mice (260). In contrast, IL-23p19 $19^{-1}$ mice had enhanced survival upon challenge with C. albicans or Aspergillus fumigatus, while p35 $5^{-/-}$mice were even more susceptible than $\mathrm{p} 40^{-/-}$mice (261). Moreover, IL-23 and IL-17 were shown to directly suppress the ability of neutrophils to kill candidal organisms (261). These findings led to the conclusion that IL-23 and IL-17 had a largely deleterious role in host defense against fungi $(261,262)$.

However, human memory $\mathrm{T}$ cells responsive to C. albicans were found to reside mainly in the Th17 subset, in contrast to memory $\mathrm{T}$ cells for MTB, which were mostly Th1 (43). Interestingly, C. albicans yeast induced human DCs to produce primarily IL-12, while C. albicans hyphae induced IL-23 exclusively (43). The candidal $\beta$-glucan curdlan was shown to induce mouse DCs to produce IL-23 by a non-TLR pathway, through binding to dectin-1 (263). This finding indicates that triggering of specific pattern recognition receptors on APCs could skew immune responses to Th17 versus Th1 pathways (264).

These apparently paradoxical results highlight the complexity of fungal infections and the host response to such pathogens. Issues to consider include differences between hyphal and yeast forms of the organism, possible differences in host responses in mice versus humans, and subtle differences between the consequences of the various genetic manipulations used in the mouse systems. IL-17R-deficient mice, for example, might lack responses to other cytokines in the IL-17 family beyond IL-17A, while IL-23-deficient mice could still develop Th17 cells. Understanding whether Th17 cells are important in anti-fungal immunity is of significant practical importance, as organisms such as Pneumocystis, Candida, and Cryptococcus are common opportunistic pathogens in immunosuppressed patients. A reasonable synthesis of current information would suggest that limited and correctly timed Th17 responses are protective, when appropriately balanced with concurrent Th1 immunity, but that uncontrolled Th17 cell activity could lead to a counter- productive level of organ inflammation. A similar suggestion has been made regarding the role of Th17 cells in host defense against Toxoplasma gondii, an obligate intracellular organism that is an important human pathogen in human immunodeficiency virus-infected individuals, newborns, other immunocompromised subjects, and sometimes in people who are otherwise apparently healthy (265).

\section{Parasites}

Parasitic infections are especially common and problematic in economically disadvantaged societies. The helminth Schistosoma mansoni can lead to serious granulomatous inflammation in the liver. In a murine model system of schistosomal hepatic inflammation, IL-17 was found to be highly pathogenic, especially in the absence of IFN- $\gamma$ in IL- $12 \mathrm{p} 35^{-1-}$ mice (266). More studies are needed concerning the Th17 response in humans naturally infected with parasitic organisms.

\section{Viruses}

Herpesvirus saimiri, which can infect and transform $\mathrm{T}$ lymphocytes from non-human primates, carries a variety of mammalian gene homologs in its genome, including genes that encode viral forms of IL-17 and the IL-8R $(4,267)$. The viral IL-17 is functionally similar to mammalian IL-17 and indeed was used to first identify the IL-17R (4). IL-17 is not required for the transforming ability of H. saimiri (268). Human viruses are not known to encode an IL-17 gene, but several can induce IL-17 responses, including herpes simplex (269), respiratory syncytial virus (RSV) (270, 271), rotavirus (272), and human T-cell leukemia virus type 1 (HTLV-1) (273). In the case of HTLV-1, the viral Tax protein, produced by infected T cells, activates the IL-17 gene promoter by engaging the CREB/ATF pathway (273). In human immunodeficiency virus infection, production of IL-17 by peripheral blood T cells is enhanced compared with control subjects, although the cause and significance of this phenomenon is not yet known (274). Exogenous IL-17 exaggerates the inflammatory response to rhinovirus (275) or vaccinia virus (276), leading in the latter instance to accelerated mortality. The proinflammatory effects of IL-17 in herpes simplex virus or RSV infections were also inferred to be detrimental overall to the host. Examples are not yet available with human pathogens that demonstrate a primary role for Th17 rather than Th1 responses in anti-viral host defenses. Rather, the role of Th17 cells in viral infections seems to be either secondary or even pathogenic.

\section{ThI7 cells and cancer}

Information from both experimental animal systems and human cancer patients suggests that IL-17 and IL-23 are generally 
favorable to the growth of tumors and that these effects outweigh their roles in the generation of T-cell anti-tumor immunity. Studies in nude mice showed that transfection of cervical carcinoma cell lines with an IL-17 cDNA led to faster growth in vivo (277). Human ovarian cancer specimens that contained IL-17 exhibited significantly greater angiogenesis (278). In general, IL-17 present in tumors is not believed to be secreted by the tumor cells themselves, with the exception of cutaneous T-cell lymphoma cells, which secrete IL-17 (279), and possibly also some pancreatic cancers (280). However, it is likely that most types of tumor cells express IL-17 receptors, as has been well documented in prostate cancer (281). In addition to angiogenesis, IL-17 can promote neutrophilic invasion of tumors (282). These inflammatory and pro-angiogenic effects of IL-17 are mediated by local production of cytokines and chemokines, by the tumors themselves (283) or more typically by adjacent tissue, stromal, and/or inflammatory cells $(279,284,285)$. When lung cancer cell lines were transfected with an IL-17 cDNA, in vitro growth was not altered, but in vivo growth in severe combined immunodeficient mice was accelerated. The tumor cells themselves were induced to secrete multiple angiogenic, not angiostatic, factors by IL-17, and neutralization of CXCR-2 abrogated the tumor-promoting effect of IL-17 in vivo. Furthermore, human lung cancer specimens that contained IL-17 had a higher vascular density on histologic analysis than those devoid of IL-1 7 (285).

In some model systems in immunocompetent mice, expression of IL-17 boosts anti-tumor immunity by contributing to the development of cytotoxic T cells (286, 287). However, in human patients with advanced ovarian cancer, Th17 cells are increased in number in the blood and especially in tumor tissue or exudates and coexist in the tumor specimens with even larger numbers of Treg cells and with some $\mathrm{CD} 8{ }^{+} \mathrm{IL}-17^{+}$cells (288). The authors of this report inferred a pathogenic role for IL-17 in cancer.

In experimental systems, IL-23 can also have striking tumorpromoting activity. In IL-12 knockout mice in which skin tumors were induced by ultraviolet irradiation, local inflammation, tumor proliferation, and expression of IL-6 and IL-23 were all significantly enhanced compared with wildtype controls (289). IL-23, but not IL-12, was shown to be overexpressed in human colon cancers (290). In a mouse system of cutaneous chemical carcinogenesis, IL-23-deficient mice were protected, while IL-12-deficient mice were especially susceptible, and protection against tumor growth correlated with $\mathrm{CD}^{+}$T-cell infiltration (290). Growth of a variety of established tumor lines in mice was also reduced by genetic deletion or antibody neutralization of IL-23 (290). It was further suggested that IL-23 might directly inhibit the ability of cytotoxic T cells to infiltrate tumors (291), although much more work is needed to adequately test this hypothesis. In contrast, IL-23, like IL-17, has unequivocal anti-tumor effects in some experimental systems that are mediated by cellular immune responses against the tumor (292). Fully satisfactory explanations for the contradictory data cited above regarding the roles of IL-17 and IL-23 in cancer are not yet available. It is possible that the effects of these cytokines will vary with different tumors, which may be associated with distinct patterns of stromal, angiogenic, and inflammatory reactions. The timing and dosage of introduction of IL-17 or IL-23 into tumor systems, and the balance with Th1 immunity and other aspects of host defense, could also be critical.

\section{ThI 7 cells and transplantation}

Evidence is accumulating for an important role of IL-17 in allograft rejection, both in rodent models and in humans. IL-17 is specifically present in kidneys undergoing rejection, both in rats and in humans (293-295). IL-17 is not found in normal kidneys or in transplants not undergoing rejection. Moreover, it is present early, and its appearance is soon followed by the local production of pro-inflammatory molecules known to be induced by IL-17. IL-17 mRNA in urinary sediment may be an early and sensitive indicator of otherwise unapparent early renal allograft rejection $(294,295)$. In both rat and human lung transplants, late damage to the allograft was found to be associated with and likely mediated by autoreactive Th17 cells specific for type V collagen that engender bronchiolitis obliterans $(296,297)$. In mouse and rat cardiac allograft models, use of a soluble IL-17R protein prolonged graft survival (298, 299). These findings help to provide a conceptual basis for therapeutic interference with Th17 cells in human organ transplantation.

\section{Conclusion}

Although information about human Th17 cells has lagged slightly behind the avalanche of new data from murine systems, it is clear that IL-17 is likely to be a cytokine of significant and potentially central importance in a diverse spectrum of human diseases. More data are needed regarding functional subsets within the Th17 cell population, the nature of the overlap between Th1 and Th17 cells, and the pathways by which Th17 responses are regulated in the human immune system. Much more needs to be learned about IL-17 production by non-CD4 ${ }^{+}$cells and about the functional importance 
of the other members of the IL-17 family, beyond IL-17A. As strategies to interfere with Th17 function enter clinical trials in immune-mediated human diseases, careful scrutiny must be given to any deleterious effects on host defenses.
While some predictions and suggested precautions can be inferred from available information, additional lessons will inevitably be learned in the course of clinical research in human subjects.

\section{References}

1. Mosmann TR, Cherwinski H, Bond MW, Giedlin MA, Coffman RL. Two types of murine helper $\mathrm{T}$ cell clone. I. Definition according to profiles of lymphokine activities and secreted proteins. J Immunol 1986;136:2348-2257.

2. Harrington LE, et al. Interleukin 17producing CD4+ effector T cells develop via a lineage distinct from the $\mathrm{T}$ helper type 1 and 2 lineages. Nat Immunol 2005;6:1123-1132.

3. Park $\mathrm{H}$, et al. A distinct lineage of CD4 T cells regulates tissue inflammation by producing interleukin 17. Nat Immunol 2005;6:1133-1141.

4. Yao Z, et al. Herpesvirus saimiri encodes a new cytokine, IL-17, which binds to a novel cytokine receptor. Immunity 1995;3:811-821

5. Yao Z, et al. Human IL-17: a novel cytokine derived from T cells. J Immunol 1995; 155:5483-5486.

6. Fossiez F, et al. T cell interleukin-17 induces stromal cells to produce proinflammatory and hematopoietic cytokines. J Exp Med 1996;183:2593-2603.

7. Murphy KM, Reiner SL. The lineage decisions of helper T cells. Nat Rev Immunol 2002;2:933-944.

8. Langrish CL, et al. IL-23 drives a pathogenic $\mathrm{T}$ cell population that induces autoimmune inflammation. J Exp Med 2005;201:233-240.

9. Aggarwal S, Ghilardi N, Xie M-H, de Sauvage FJ, Gurney AL. Interleukin-23 promotes a distinct CD4 $\mathrm{T}$ cell activation state characterized by the production of interleukin-17. J Biol Chem 2003;278:1910-1914.

10. Bettelli E, et al. Reciprocal developmental pathways for the generation of pathogenic effector TH1 7 and regulatory T cells. Nature 2006;441:235-238.

11. Mangan PR, et al. Transforming growth factor-beta induces development of the TH1 7 lineage. Nature 2006;441:231-234.

12. Veldhoen M, Hocking RJ, Atkins CJ, Locksley RM, Stockinger B. TGFbeta in the context of an inflammatory cytokine milieu supports de novo differentiation of IL-17-producing T cells. Immunity 2006;24:179-189.

13. Sutton C, Brereton C, Keogh B, Mills KHG, Lavelle EC. A crucial role for interleukin (IL)- 1 in the induction of IL-17-producing $\mathrm{T}$ cells that mediate autoimmune encephalomyelitis. J Exp Med

2006;203:1685-1691.

14. Nakae S, Iwakura Y, Suto H, Galli SJ. Phenotypic differences between Th 1 and Th1 7 cells and negative regulation of Th1 cell differentiation by IL-17. J Leukoc Biol 2007;81:1258-1268.

15. Li MO, Wan YY, Sanjabi S, Robertson A-KL, Flavell RA. Transforming growth factor-beta; regulation of immune responses. Annu Rev Immunol 2006;24:99-146.

16. Xu L, Kitani A, Fuss I, Strober W. Cutting edge: regulatory $\mathrm{T}$ cells induce $\mathrm{CD} 4+$ CD25 - Foxp3- T cells or are self-induced to become Th17 cells in the absence of exogenous TGF-beta. J Immunol 2007; 178:6725-6729.

17. Annunziato F, et al. Phenotypic and functional features of human Th17 cells. J Exp Med 2007;204:1849-1861.

18. Evans HG, Suddason T, Jackson I, Taams LS, Lord GM. Optimal induction of T helper 17 cells in humans requires $\mathrm{T}$ cell receptor ligation in the context of Toll-like receptoractivated monocytes. Proc Natl Acad Sci USA 2007;104:17034-17039.

19. Acosta-Rodriguez EV, Napolitani G, Lanzavecchia A, Sallusto F. Interleukins 1 beta and 6 but not transforming growth factor-beta are essential for the differentiation of interleukin 17-producing human T helper cells. Nat Immunol 2007;8:942-949.

20. Wilson NJ, et al. Development, cytokine profile and function of human interleukin 17-producing helper T cells. Nat Immunol 2007;8:950-957.

21. Chen Z, Tato CM, Muul L, Laurence A, O'Shea JJ. Distinct regulation of interleukin17 in human T helper lymphocytes. Arthritis Rheum 2007;56:2936-2946.

22. Yen D, et al. IL-23 is essential for T cellmediated colitis and promotes inflammation via IL-17 and IL-6. J Clin Invest 2006;116:1310-1316.

23. Manel N, Unutmaz D, Littman DR. The differentiation of human Th-17 cells requires transforming growth factor-beta and induction of the nuclear receptor RORgamma-t. Nature Immunology 2008; e-publication, May 42008.

24. Volpe E, Servant N, Zollinger R, Bogiatzi SI, Hupe P, Barillot E, Soumelis V. A critical function for transforming growth factorbeta, interleukin 23 and proinflammatory cytokines in driving and modulating human Th-1 7 responses. Nature Immunology 2008; e-publication, May 42008.

25. Amadi-Obi A, et al. TH17 cells contribute to uveitis and scleritis and are expanded by IL-2 and inhibited by IL-27/STAT1. Nat Med 2007;13:711-718.

26. Hoeve MA, et al. Divergent effects of IL-12 and IL-23 on the production of IL-1 7 by human T cells. Eur J Immunol 2006;36:661-670.

27. Ivanov II, et al. The orphan nuclear receptor ROR [gamma]t directs the differentiation program of proinflammatory IL-17+ T helper cells. Cell 2006;126:1121-1133.

28. Yang XO, et al. STAT3 regulates cytokinemediated generation of inflammatory helper T cells. J Biol Chem 2007;282:9358-9363.

29. Chen Z, et al. Selective regulatory function of Socs3 in the formation of IL-17-secreting T cells. Proc Natl Acad Sci USA 2006;103:8137-8142.

30. Mathur AN, et al. STAT3 and STAT4 direct development of IL-17-secreting Th cells. J Immunol 2007;1 78:4901-4907.

31. Nishihara M, et al. IL-6-gp130-STAT3 in T cells directs the development of IL-17+ Th with a minimum effect on that of Treg in the steady state. Int Immunol 2007;19:695-702.

32. Wei L, Laurence A, Elias KM, O’Shea JJ. IL21 Is produced by Th17 cells and drives IL17 production in a STAT3-dependent manner. J Biol Chem 2007;282:34605-34610.

33. Fantini MC, et al. IL-21 regulates experimental colitis by modulating the balance between Th1 and Th1 7 cells. Eur J Immunol 2007;37:3155-3163.

34. Zhou L, et al. IL-6 programs TH-17 cell differentiation by promoting sequential engagement of the IL-2 1 and IL-23 pathways. Nat Immunol 2007;8:967-974.

35. Korn T, et al. IL-21 initiates an alternative pathway to induce proinflammatory TH1 7 cells. Nature 2007;448:484-487.

36. Nurieva R, et al. Essential autocrine regulation by IL-2 1 in the generation of inflammatory T cells. Nature 2007;448:480-483

37. Peluso I, et al. IL-21 counteracts the regulatory $\mathrm{T}$ cell-mediated suppression of human CD4+ T lymphocytes. J Immunol 2007; 178:732-739. 
38. Onoda T, et al. Human CD4+ central and effector memory $\mathrm{T}$ cells produce IL-21: effect on cytokine-driven proliferation of CD4 + T cell subsets. Int Immunol 2007;19:1191-1199.

39. Kuestner RE, et al. Identification of the IL-17 receptor related molecule IL-17RC as the receptor for IL-17F. J Immunol 2007; 179:5462-5473.

40. Wright JF, et al. Identification of an interleukin 17F/17A heterodimer in activated human CD4+ T cells. J Biol Chem 2007;282:13447-13455.

41. Liang SC, et al. An IL-17F/A heterodimer protein is produced by mouse Th17 cells and induces airway neutrophil recruitment. J Immunol 2007;1 179:7791-7799.

42. Zheng Y, et al. Interleukin-22, a TH17 cytokine, mediates IL-23-induced dermal inflammation and acanthosis. Nature 2007;445:648-651.

43. Acosta-Rodriguez EV, et al. Surface phenotype and antigenic specificity of human interleukin 17-producing T helper memory cells. Nat Immunol 2007;8:639-646.

44. Liang SC, et al. Interleukin (IL)-22 and IL-17 are coexpressed by Th17 cells and cooperatively enhance expression of antimicrobial peptides. J Exp Med 2006;203:2271-2279.

45. Chung Y, Yang X, Chang SH, Ma L, Tian Q, Dong C. Expression and regulation of IL-22 in the IL-17-producing CD4+ T lymphocytes. Cell Res 2006;16:902-907.

46. Boniface K, Bernard F-X, Garcia M, Gurney AL, Lecron J-C, Morel F. IL-22 inhibits epidermal differentiation and induces proinflammatory gene expression and migration of human keratinocytes. J Immunol 2005;1 74:3695-3702.

47. Wolk K, et al. IL-22 regulates the expression of genes responsible for antimicrobial defense, cellular differentiation, and mobility in keratinocytes: a potential role in psoriasis. Eur J Immunol 2006;36:1309-1323.

48. Andoh A, et al. Interleukin-22, a member of the IL-10 subfamily, induces inflammatory responses in colonic subepithelial myofibroblasts. Gastroenterol 2005;129:969-984.

49. Zenewicz LA, Yancopoulos GD, Valenzuela DM, Murphy AJ, Karow M, Flavell RA. Interleukin-22 but not interleukin-17 provides protection to hepatocytes during acute liver inflammation. Immunity 2007; 27:647-659.

50. Anderson CF, Oukka M, Kuchroo VJ, Sacks D. CD4+CD25-Foxp3-Th1 cells are the source of IL-10-mediated immune suppression in chronic cutaneous leishmaniasis. J Exp Med 2007;204:285-297.

51. Jankovic D, et al. Conventional T-bet+ Foxp3-Th1 cells are the major source of host-protective regulatory IL-10 during in- tracellular protozoan infection. J Exp Med 2007;204:273-283.

52. McGeachy MJ, et al. TGF-[beta] and IL-6 drive the production of IL-17 and IL- 10 by $\mathrm{T}$ cells and restrain TH-17 cell-mediated pathology. Nat Immunol 2007;8:1390-1397.

53. Stumhofer JS, et al. Interleukins 27 and 6 induce STAT3-mediated $\mathrm{T}$ cell production of interleukin 10. Nat Immunol 2007;8:1363-1371.

54. Hirota K, et al. Preferential recruitment of CCR6-expressing Th17 cells to inflamed joints via CCL20 in rheumatoid arthritis and its animal model. J Exp Med 2007;204:2803-2812.

55. Lundy SK, Lira SA, Smit JJ, Cook DN, Berlin AA, Lukacs NW. Attenuation of allergeninduced responses in CCR6-/- mice is dependent upon altered pulmonary T lymphocyte activation. J Immunol 2005; 174:2054-2060

56. Teraki Y, Miyake A, Takebayashi R, Shiohara T. Homing receptor and chemokine receptor on intraepidermal T cells in psoriasis vulgaris. Clin Exp Dermatol 2004;29:658-663.

57. Varona R, Cadenas V, Flores J, Martínez AC, Márquez G. CCR6 has a non-redundant role in the development of inflammatory bowel disease. Eur J Immunol 2003;33:2937-2946.

58. Ruth J, et al. Role of macrophage inflammatory protein-3alpha and its ligand CCR6 in rheumatoid arthritis. Lab Invest 2003;83:579-588.

59. Kao C-Y, et al. Up-regulation of CC chemokine ligand 20 expression in human airway epithelium by IL-17 through a JAKindependent but MEK/NF- kappa\} B-dependent signaling pathway. J Immunol 2005;175:6676-6685.

60. Chabaud M, Page G, Miossec P. Enhancing effect of IL-1, IL-17, and TNF- \{alpha\} on macrophage inflammatory protein-3 \{alpha\} production in rheumatoid arthritis: regulation by soluble receptors and Th2 cytokines. J Immunol 2001;167:6015-6020.

61. Sato W, Aranami T, Yamamura T. Cutting edge: human Th17 cells are identified as bearing CCR2 + CCR5- phenotype. J Immunol 2007; 1 78:7525-7529.

62. Arican OAM, Sasmaz S, Ciragil P. Serum levels of TNF-alpha, IFN-gamma, IL-6, IL-8, IL-12, IL-17, and IL-18 in patients with active psoriasis and correlation with disease severity. Mediators Inflamm 2005;2005:273-279.

63. Chan JR, et al. IL-23 stimulates epidermal hyperplasia via TNF and IL-20R2-dependent mechanisms with implications for psoriasis pathogenesis. J Exp Med 2006;203:2577-2587.
64. Villadsen LS, et al. Resolution of psoriasis upon blockade of IL-15 biological activity in a xenograft mouse model. J Clin Invest 2003;112:1571-1580.

65. Lee E, et al. Increased expression of interleukin 23 p19 and p40 in lesional skin of patients with psoriasis vulgaris. J Exp Med 2004;199:125-130.

66. Piskin G, Sylva-Steenland RMR, Bos JD, Teunissen MBM. In vitro and in situ expression of IL- 23 by keratinocytes in healthy skin and psoriasis lesions: enhanced expression in psoriatic skin. J Immunol 2006;176:1908-1915.

67. Albanesi C, Scarponi C, Cavani A, Federici M, Nasorri F, Girolomoni G. Interleukin-17 is produced by both Th1 and Th2 lymphocytes, and modulates interferon-[gamma]and interleukin-4-induced activation of human keratinocytes. J Invest Dermatol 2000;115:81-87.

68. Homey B, et al. Up-regulation of macrophage inflammatory protein-3 $\{$ alpha $\}$ / CCL20 and CC chemokine receptor 6 in psoriasis. J Immunol 2000;164:6621-6632.

69. Krueger GG, et al. A human interleukin-12/ 23 monoclonal antibody for the treatment of psoriasis. N Engl J Med 2007;356:580-592.

70. Toichi E, et al. An anti-IL-12p40 antibody down-regulates type 1 cytokines, chemokines, and IL-12/IL-23 in psoriasis. J Immunol 2006;1 77:4917-4926.

71. Zaba LC, et al. Amelioration of epidermal hyperplasia by TNF inhibition is associated with reduced Th17 responses. J Exp Med 2007;204:3183-3194.

72. Mauritz N, Holmdahl R, Jonsson R, Van der Meide P, Scheynius A, Klareskog L. Treatment with gamma-interferon triggers the onset of collagen arthritis in mice. Arthritis Rheum 1988;31:1297-1304.

73. Cooper SM, Sriram S, Ranges GE. Suppression of murine collagen-induced arthritis with monoclonal anti-Ia antibodies and augmentation with IFN-gamma. J Immunol 1988;141:1958-1962.

74. Manoury-Schwartz B, et al. High susceptibility to collagen-induced arthritis in mice lacking IFN-gamma receptors. J Immunol 1997; 158:5501-5506.

75. Vermeire K, Heremans H, Vandeputte M, Huang S, Billiau A, Matthys P. Accelerated collagen-induced arthritis in IFN-gamma receptor-deficient mice. J Immunol 1997;158:5507-5513.

76. Chu C-Q, Swart D, Alcorn D, Tocker J, Elkon KB. Interferon-gamma regulates susceptibility to collagen-induced arthritis through suppression of interleukin-17. Arthritis Rheum 2007;56: 1145-1151. 
77. Chu CQ, Song Z, Mayton L, Wu B, Wooley PH. IFN \{gamma\} deficient C57BL/ 6 (H2b) mice develop collagen induced arthritis with predominant usage of $\mathrm{T}$ cell receptor $\mathrm{V}\{$ beta 6 and $\mathrm{V}$ \{beta\} 8 in arthritic joints. Ann Rheum Dis 2003;62:983-990.

78. Guedez Y, et al. Genetic ablation of interferon-gamma up-regulates interleukin-1 beta expression and enables the elicitation of collagen-induced arthritis in a nonsusceptible mouse strain. Arthritis Rheum 2001;44:2413-2424.

79. Murphy CA, et al. Divergent pro- and antiinflammatory roles for IL-23 and IL-12 in joint autoimmune inflammation. J Exp Med 2003;198:1951-1957.

80. Irmler IM, Gajda M, Brauer R. Exacerbation of antigen-induced arthritis in IFN\{gamma\}-deficient mice as a result of unrestricted IL-17 response. J Immunol 2007;179:6228-6236.

81. Boissier MC, et al. Biphasic effect of interferon-gamma in murine collagen-induced arthritis. Eur J Immunol 1995;25:1184-1190.

82. Finnegan A, Mikecz K, Tao P, Glant TT. Proteoglycan (aggrecan)-induced arthritis in BALB/c mice is a Th1-type disease regulated by Th2 cytokines. J Immunol 1999;163:5383-5390.

83. Nakae S, Nambu A, Sudo K, Iwakura Y. Suppression of immune induction of collagen-induced arthritis in IL-17-deficient mice. J Immunol 2003;171:6173-6177.

84. Lubberts E, et al. Treatment with a neutralizing anti-murine interleukin-17 antibody after the onset of collagen-induced arthritis reduces joint inflammation, cartilage destruction, and bone erosion. Arthritis Rheum 2004;50:650-659.

85. Bush KA, Farmer KM, Walker JS, Kirkham BW. Reduction of joint inflammation and bone erosion in rat adjuvant arthritis by treatment with interleukin-17 receptor IgG1 Fc fusion protein. Arthritis Rheum 2002;46:802-805.

86. Koenders MI, et al. Interleukin-17 receptor deficiency results in impaired synovial expression of interleukin-1 and matrix metalloproteinases 3, 9, and 13 and prevents cartilage destruction during chronic reactivated streptococcal cell wall-induced arthritis. Arthritis Rheum 2005;52:3239-3247.

87. Lubberts E, et al. Requirement of IL-17 receptor signaling in radiation-resistant cells in the joint for full progression of destructive synovitis. J Immunol 2005; 175:3360-3368.

88. Nakae S, Saijo S, Horai R, Sudo K, Mori S, Iwakura Y. IL-17 production from activated $\mathrm{T}$ cells is required for the spontaneous development of destructive arthritis in mice deficient in IL-1 receptor antagonist. Proc Natl Acad Sci USA 2003;100:5986-5990.

89. Hirota K, et al. T cell self-reactivity forms a cytokine milieu for spontaneous development of IL-17+Th cells that cause autoimmune arthritis. J Exp Med 2007;204:41-47.

90. Hwang SYKH. Expression of IL-17 homologs and their receptors in the synovial cells of rheumatoid arthritis patients. Mol Cells 2005;19:180-184.

91. Chabaud M, et al. Human interleukin-17: a T cell-derived proinflammatory cytokine produced by the rheumatoid synovium. Arthritis Rheum 1999;42:963-970.

92. Ziolkowska M, et al. High levels of IL-17 in rheumatoid arthritis patients: IL-15 triggers in vitro IL-17 production via cyclosporin A-sensitive mechanism. J Immunol 2000; 164:2832-2838.

93. Kirkham BW, et al. Synovial membrane cytokine expression is predictive of joint damage progression in rheumatoid arthritis: a two-year prospective study (the DAMAGE study cohort). Arthritis Rheum 2006;54:1122-1131.

94. Lundy S, Sarkar S, Tesmer L, Fox D. Cells of the synovium in rheumatoid arthritis. T lymphocytes. Arthritis Res Ther 2007;9:202.

95. Kim K-W, et al. Up-regulation of stromal cell-derived factor 1 (CXCL12) production in rheumatoid synovial fibroblasts through interactions with $\mathrm{T}$ lymphocytes: role of interleukin-17 and CD40L-CD40 interaction. Arthritis Rheum 2007;56:1076-1086.

96. Ryu SLJ, Kim SI. IL-17 increased the production of vascular endothelial growth factor in rheumatoid arthritis synoviocytes. Clin Rheumatol 2006;25:16-20.

97. Kotake S, et al. IL-17 in synovial fluids from patients with rheumatoid arthritis is a potent stimulator of osteoclastogenesis. J Clin Invest 1999;103:1345-1352.

98. Miranda-Carús M-E, et al. Peripheral blood $\mathrm{T}$ lymphocytes from patients with early rheumatoid arthritis express RANKL and interleukin-15 on the cell surface and promote osteoclastogenesis in autologous monocytes. Arthritis Rheum 2006;54:1151-1164.

99. Sato K, et al. Th17 functions as an osteoclastogenic helper $\mathrm{T}$ cell subset that links $\mathrm{T}$ cell activation and bone destruction. J Exp Med 2006;203:2673-2682.

100. Cho M-L, et al. STAT3 and NF- $\{$ kappa $\}$ B signal pathway Is required for IL-23mediated IL-17 production in spontaneous arthritis animal model IL-1 receptor antagonist-deficient mice. J Immunol 2006; 176:5652-5661.

101. Lubberts E, et al. IL-1-independent role of IL-17 in synovial inflammation and joint destruction during collagen-induced arthritis. J Immunol 2001;167:1004-1013.

102. Koenders MI, et al. Interleukin- 17 acts independently of TNF-\{alpha\} under arthritic conditions. J Immunol 2006; 176:6262-6269.

103. Koenders MI, et al. Induction of cartilage damage by overexpression of $\mathrm{T}$ cell interleukin-17A in experimental arthritis in mice deficient in interleukin-1. Arthritis Rheum 2005;52:975-983.

104. Lubberts E, Koenders M, van den Berg W. The role of $\mathrm{T}$ cell interleukin-17 in conducting destructive arthritis: lessons from animal models. Arthritis Res Ther 2005; 7:29-37.

105. Jüngel A, et al. Expression of interleukin-21 receptor, but not interleukin-21, in synovial fibroblasts and synovial macrophages of patients with rheumatoid arthritis. Arthritis Rheum 2004;50:1468-1476.

106. Li J, Shen W, Kong K, Liu Z. Interleukin-21 induces T-cell activation and proinflammatory cytokine secretion in rheumatoid arthritis. Scand J Immunol 2006;64:515-522.

107. Young DA, et al. Blockade of the interleukin21/interleukin-21 receptor pathway ameliorates disease in animal models of rheumatoid arthritis. Arthritis Rheum 2007;56:1152-1163.

108. Kim HR, Kim HS, Park MK, Cho ML, Lee SH, Kim HY. The clinical role of IL-23p19 in patients with rheumatoid arthritis. Scand J Rheumatol 2007;36:259-264.

109. Kim HR, et al. Up-regulation of IL-23p19 expression in rheumatoid arthritis synovial fibroblasts by IL-17 through PI3-kinase-, NF- $\{$ kappa $\}$ B- and p38 MAPK-dependent signalling pathways. Rheumatology 2007; 46:57-64.

110. Lee HS, Remmers EF, Le JM, Kastner DL, Bae SC, Gregersen PK. Association of STAT4 with rheumatoid arthritis in the Korean population. Mol Med 2007;13:455-460.

111. Remmers EF, et al. STAT4 and the risk of rheumatoid arthritis and systemic lupus erythematosus. N Engl J Med 2007;357:977-986.

112. Hildner KM, et al. Targeting of the transcription factor STAT4 by antisense phosphorothioate oligonucleotides suppresses collagen-induced arthritis. J Immunol 2007; 178:3427-3436.

113. Ikeuchi $\mathrm{H}$, et al. Expression of interleukin22 in rheumatoid arthritis: potential role as a proinflammatory cytokine. Arthritis Rheum 2005;52:1037-1046.

114. Miranda-Carus M-E, Balsa A, Benito-Miguel M, Perez de Ayala C, Martin-Mola E. IL-15 and the initiation of cell contact-dependent synovial fibroblast-T lymphocyte cross-talk 
in rheumatoid arthritis: effect of methotrexate. J Immunol 2004;173:1463-1476.

115. Yoshihara K, Yamada H, Hori A, Yajima T, Kubo C, Yoshikai Y. IL-15 exacerbates collagen-induced arthritis with an enhanced $\mathrm{CD} 4+\mathrm{T}$ cell response to produce IL-17. Eur J Immunol 2007;37:2744-2752.

116. Ferrari-Lacraz S, et al. Targeting IL-15 receptor-bearing cells with an antagonist mutant IL-15/Fc protein prevents disease development and progression in murine collagen-induced arthritis. J Immunol 2004; 173:5818-5826.

117. Yamamura $Y$, et al. Effector function of resting T cells: activation of synovial fibroblasts. J Immunol 2001;166:2270-2275.

118. Tsai $C$, et al. Responsiveness of human $T$ lymphocytes to bacterial superantigens presented by cultured rheumatoid arthritis synoviocytes. Arthritis Rheum 1996;39:125-136.

117. Brennan FM, Hayes AL, Ciesielski CJ, Green P, Foxwell BMJ, Feldmann M. Evidence that rheumatoid arthritis synovial T cells are similar to cytokine-activated T cells: involvement of phosphatidylinositol 3-kinase and nuclear factor kappa-B pathways in tumor necrosis factor alpha production in rheumatoid arthritis. Arthritis Rheum 2002;46:31-41.

120. Tran CN, et al. Molecular interactions between T Cells and fibroblast-like synoviocytes: role of membrane tumor necrosis factor-\{alpha\} on cytokine-activated T cells. Am J Pathol 2007;1 17:1588-1598.

121. Stanley KT, VanDort C, Motyl C, Endres J, Fox DA. Immunocompetent properties of human osteoblasts: interactions with $\mathrm{T}$ lymphocytes. J Bone Miner Res 2006;21:29-36.

122. Morita Y, et al. Dendritic cells genetically engineered to express IL-4 inhibit murine collagen-induced arthritis. J Clin Invest 2001;107:1275-1284.

123. Sarkar S, Tesmer LA, Hindnavis V, Endres JL, Fox DA. Interleukin-17 as a molecular target in immune-mediated arthritis: immunoregulatory properties of genetically modified murine dendritic cells that secrete interleukin-4. Arthritis Rheum 2007;56:89-100.

124. Lubberts E, et al. IL-4 gene therapy for collagen arthritis suppresses synovial IL-17 and osteoprotegerin ligand and prevents bone erosion. J Clin Invest 2000; 105:1697-1710.

125. Kurasawa K, et al. Increased interleukin-17 production in patients with systemic sclerosis. Arthritis Rheum 2000;43:2455-2463.

126. Distler JHW, et al. Expression of interleukin21 receptor in epidermis from patients with systemic sclerosis. Arthritis Rheum 2005;52:856-864.
127. Baechler EC, Gregersen PK, Behrens TW. The emerging role of interferon in human systemic lupus erythematosus. Curr Opin Immunol 2004;16:801-807.

128. Meyers JA, et al. Blockade of TLR9 agonistinduced type I interferons promotes inflammatory cytokine IFN-[gamma] and IL-1 7 secretion by activated human PBMC. Cytokine 2006;35:235-246.

129. Wong CK, Ho CY, Li EK, Lam CWK. Elevation of proinflammatory cytokine (IL-18, IL-17, IL-12) and Th2 cytokine (IL-4) concentrations in patients with systemic lupus erythematosus. Lupus 2000;9:589-593.

130. Kang H-K, Liu M, Datta SK. Low-dose peptide tolerance therapy of lupus generates plasmacytoid dendritic cells that cause expansion of autoantigen-specific regulatory $\mathrm{T}$ cells and contraction of inflammatory Th17 cells. J Immunol 2007; 178:7849-7858.

131. Singh R, Aggarwal A, Misra R. Th1/Th17 cytokine profiles in patients with reactive arthritis/undifferentiated spondyloarthropathy. J Rheumatol 2007;34:2285-2290.

132. Merrill JE. Proinflammatory and antiinflammatory cytokines in multiple sclerosis and central nervous system acquired immunodeficiency syndrome. J Immunother 1992;12:167-170.

133. Woodroofe MN, Cuzner ML. Cytokine mRNA expression in inflammatory multiple sclerosis lesions: detection by non-radioactive in situ hybridization. Cytokine 1993;5:583-588.

134. Porrini AM, Reder AT. IFN-gamma, IFNbeta, and PGE1 affect monokine secretion: relevance to monocyte activation in multiple sclerosis. Cell Immunol 1994;157:428-438.

135. Rovaris M, et al. Patterns of disease activity in multiple sclerosis patients: a study with quantitative gadolinium-enhanced brain MRI and cytokine measurement in different clinical subgroups. J Neurol 1996;243:536-542.

136. Matusevicius D, et al. Interleukin-17 mRNA expression in blood and CSF mononuclear cells is augmented in multiple sclerosis. Mult Scler 1999;5:101-104.

137. Zhang GX, et al. Induction of experimental autoimmune encephalomyelitis in IL-12 receptor-beta 2-deficient mice: IL-12 responsiveness is not required in the pathogenesis of inflammatory demyelination in the central nervous system. J Immunol 2003; 170:2153-2160.

138. Vaknin-Dembinsky A, Balashov K, Weiner HL. IL-23 is increased in dendritic cells in multiple sclerosis and down-regulation of IL-23 by antisense oligos increases dendritic cell IL-10 production. J Immunol 2006;176:7768-7774.
139. Correale J, Farez M. Monocyte-derived dendritic cells in multiple sclerosis: the effect of bacterial infection. J Neuroimmunol 2007;190:177-189.

140. Bailey SL, Schreiner B, McMahon EJ, Miller SD. CNS myeloid DCs presenting endogenous myelin peptides 'preferentially' polarize $\mathrm{CD} 4+\mathrm{T}(\mathrm{H})-17$ cells in relapsing EAE. Nat Immunol 2007;8:172-180.

141. Chen Y, et al. Anti-IL-23 therapy inhibits multiple inflammatory pathways and ameliorates autoimmune encephalomyelitis. J Clin Invest 2006;116:1317-1326.

142. Stumhofer JS, et al. Interleukin 27 negatively regulates the development of interleukin 17-producing $\mathrm{T}$ helper cells during chronic inflammation of the central nervous system. Nat Immunol 2006;7:937-945.

143. Batten $\mathrm{M}$, et al. Interleukin 27 limits autoimmune encephalomyelitis by suppressing the development of interleukin 17producing T cells. Nat Immunol 2006;7:929-936.

144. Ishizu $\mathrm{T}$, et al. Intrathecal activation of the IL-17/IL-8 axis in opticospinal multiple sclerosis. Brain 2005;128:988-1002.

145. Kebir H, et al. Human $\mathrm{T}(\mathrm{H}) 17$ lymphocytes promote blood-brain barrier disruption and central nervous system inflammation. Nat Med 2007;13:1173-1175.

146. Fainardi E, et al. Cerebrospinal fluid and serum levels and intrathecal production of active matrix metalloproteinase-9 (MMP-9) as markers of disease activity in patients with multiple sclerosis. Mult Scler 2006;12:294-301.

147. Yong VW, Zabad RK, Agrawal S, Goncalves Dasilva A, Metz LM. Elevation of matrix metalloproteinases (MMPs) in multiple sclerosis and impact of immunomodulators. J Neurol Sci 2007;259:79-84.

148. Furukawa Y, Kobuke K, Matsumori A. Role of cytokines in autoimmune myocarditis and cardiomyopathy. Autoimmunity 2001;34:165-168.

149. Rangachari M, et al. T-bet negatively regulates autoimmune myocarditis by suppressing local production of interleukin 17. J Exp Med 2006;203:2009-2019.

150. Sonderegger I, et al. Neutralization of IL-17 by active vaccination inhibits IL-23dependent autoimmune myocarditis. Eur J Immunol 2006;36:2849-2856.

151. Cortez DM, et al. Interleukin-17 stimulates MMP1 expression in primary human cardiac fibroblasts Via p38 MAPK and ERK1/2-dependent C/EBP \{beta\}, NF- $\{$ kappa $\}$ B, and AP-1 activation. Am J Physiol Heart Circ Physiol 2007; 293:H3356-H3365.

152. Ulukus M, Arici A. Immunology of endometriosis. Minerva Ginecol 2005;57:237-248. 
153. Inagaki J, Kondo A, Lopez LR, Shoenfeld Y, Matsuura E. Pregnancy loss and endometriosis: pathogenic role of anti-laminin-1 autoantibodies. Ann NY Acad Sci 2005;1051:174-184.

154. Zhang X, Xu H, Lin J, Qian Y, Deng L. Peritoneal fluid concentrations of interleukin-17 correlate with the severity of endometriosis and infertility of this disorder. BJOG 2005;112:1153-1155.

155. Damico FM, Kiss S, Young LH. VogtKoyanagi-Harada disease. Semin Ophthalmol 2005;20:183-190.

156. Chi W, et al. IL-23 promotes CD $4+\mathrm{T}$ cells to produce IL-17 in Vogt-Koyanagi-Harada disease. J Allergy Clin Immunol 2007;119:1218-1224.

157. Peng Y, Han G, Shao H, Wang Y, Kaplan HJ, Sun D. Characterization of IL-17+interphotoreceptor retinoid-binding protein-specific $\mathrm{T}$ cells in experimental autoimmune uveitis. Invest Ophthalmol Vis Sci 2007;48:4153-4161.

158. Bendtzen K, Buschard K, Diamant M, Horn T, Svenson M. Possible role of IL-1, TNFalpha, and IL-6 in insulin-dependent diabetes mellitus and autoimmune thyroid disease. Thyroid Cell Group. Lymphokine Res 1989;8:335-340.

159. Dogan Y, Akarsu S, Ustundag B, Yilmaz E, Gurgoze MK. Serum IL-1 beta, IL-2, and IL-6 in insulin-dependent diabetic children. Mediators Inflamm 2006;2006:59206.

160. Wilson CA, et al. IL-1 beta modulation of spontaneous autoimmune diabetes and thyroiditis in the BB rat. J Immunol 1990;144:3784-3788.

161. Mensah-Brown EP, Shahin A, Al-Shamisi M, Wei X, Lukic ML. IL-23 leads to diabetes induction after subdiabetogenic treatment with multiple low doses of streptozotocin. Eur J Immunol 2006;36:216-223.

162. Chen K, Wei Y, Sharp GC, Braley-Mullen H. Decreasing TNF-alpha results in less fibrosis and earlier resolution of granulomatous experimental autoimmune thyroiditis. J Leukoc Biol 2007;81:306-314.

163. Cooke A. Th17 cells in inflammatory conditions. Rev Diabet Stud 2006;3: 72-75.

164. Molet S, et al. IL-17 is increased in asthmatic airways and induces human bronchial fibroblasts to produce cytokines. J Allergy Clin Immunol 2001;108:430-438.

165. Barczyk A, Pierzchala W, Sozanska E. Interleukin-17 in sputum correlates with airway hyperresponsiveness to methacholine. Respir Med 2003;97:726-733.

166. Bullens DM, et al. IL-17 mRNA in sputum of asthmatic patients: linking $\mathrm{T}$ cell driven inflammation and granulocytic influx? Respir Res 2006;7:135
167. Wong CK, et al. Proinflammatory cytokines (IL-17, IL-6, IL-18 and IL-12) and Th cytokines (IFN-gamma, IL-4, IL-10 and IL-13) in patients with allergic asthma. Clin Exp Immunol 2001;125:177-183.

168. Hashimoto T, Akiyama K, Kobayashi N, Mori A. Comparison of IL-17 production by helper T cells among atopic and nonatopic asthmatics and control subjects. Int Arch Allergy Immunol 2005;137 (Suppl.):51-54.

169. Linden A. Role of interleukin-17 and the neutrophil in asthma. Int Arch Allergy Immunol 2001;126:179-184.

170. Dragon S, Rahman MS, Yang J, Unruh H, Halayko AJ, Gounni AS. IL-17 enhances IL-1 beta-mediated CXCL-8 release from human airway smooth muscle cells. Am J Physiol Lung Cell Mol Physiol 2007;292:L1023-L1029.

171. Henness S, Johnson CK, Ge Q, Armour CL, Hughes JM, Ammit AJ. IL-17 A augments TNF-alpha-induced IL-6 expression in airway smooth muscle by enhancing mRNA stability. J Allergy Clin Immunol 2004;114:958-964.

172. Rahman MS, Yamasaki A, Yang J, Shan L, Halayko AJ, Gounni AS. IL-17A induces eotaxin-1/CC chemokine ligand 11 expression in human airway smooth muscle cells: role of MAPK (Erk1/2, JNK, and p38) pathways. J Immunol 2006;177:4064-4071.

173. van den Berg A, et al. Interleukin-17 induces hyperresponsive interleukin-8 and interleukin- 6 production to tumor necrosis factor-alpha in structural lung cells. Am J Respir Cell Mol Biol 2005;33:97-104.

174. Chen Y, Thai P, Zhao YH, Ho YS, DeSouza MM, Wu R. Stimulation of airway mucin gene expression by interleukin (IL)-17 through IL-6 paracrine/autocrine loop. J Biol Chem 2003;278:17036-17043.

175. Linden A. Rationale for targeting interleukin-17 in the lungs. Curr Opin Investig Drugs 2003;4:1304-1312.

176. Chakir J, et al. Airway remodeling-associated mediators in moderate to severe asthma: effect of steroids on TGF-beta, IL11, IL-17, and type I and type III collagen expression. J Allergy Clin Immunol 2003;111:1293-1298.

177. van Beelen AJ, Teunissen MB, Kapsenberg ML, de Jong EC. Interleukin-17 in inflammatory skin disorders. Curr Opin Allergy Clin Immunol 2007;7:374-381.

178. Nakae $S$, et al. Antigen-specific T cell sensitization is impaired in IL-17-deficient mice, causing suppression of allergic cellular and humoral responses. Immunity 2002;17:375-387.
179. Miraglia del Giudice M, et al. Immune dysregulation in atopic dermatitis. Allergy Asthma Proc 2006;27:451-455.

180. Toda $\mathrm{M}$, et al. Polarized in vivo expression of IL-1 1 and IL-17 between acute and chronic skin lesions. J Allergy Clin Immunol 2003;111:875-881.

181. He D, Wu L, Kim HK, Li H, Elmets CA, Xu H CD8+IL-17-producing T cells are important in effector functions for the elicitation of contact hypersensitivity responses. J Immunol 2006;1 177:6852-6858.

182. Beeton C, et al. Kv1.3 channels are a therapeutic target for $\mathrm{T}$ cell-mediated autoimmune diseases. Proc Natl Acad Sci USA 2006;103:17414-17419.

183. Azam P, Sankaranarayanan A, Homerick D, Griffey S, Wulff $\mathrm{H}$. Targeting effector memory T cells with the small molecule Kv1.3 blocker PAP-1 suppresses allergic contact dermatitis. J Invest Dermatol 2007;127:1419-1429.

184. Albanesi C, Cavani A, Girolomoni G. IL-17 is produced by nickel-specific $\mathrm{T}$ lymphocytes and regulates ICAM-1 expression and chemokine production in human keratinocytes: synergistic or antagonist effects with IFNgamma and TNF-alpha. J Immunol 1999;162:494-502.

185. Zhang Z, Hinrichs DJ, Lu H, Chen H, Zhong W, Kolls JK. After interleukin-12p40, are interleukin-23 and interleukin-17 the next therapeutic targets for inflammatory bowel disease? Int Immunopharmacol 2007;7:409-416.

186. Hue $\mathrm{S}$, et al. Interleukin-23 drives innate and $\mathrm{T}$ cell-mediated intestinal inflammation. J Exp Med 2006;203:2473-2483.

187. Kullberg MC, et al. IL-23 plays a key role in Helicobacter hepaticus-induced T cell-dependent colitis. J Exp Med 2006;203:2485-2494.

188. Mannon PJ, et al. Anti-interleukin-12 antibody for active Crohn's disease. N Engl J Med 2004;351:2069-2079.

189. Duerr RH, et al. A genome-wide association study identifies IL23R as an inflammatory bowel disease gene. Science 2006;314:1461-1463.

190. Burakoff $\mathrm{R}$, et al. A phase $1 / 2 \mathrm{~A}$ trial of STA 5326, an oral interleukin-12/23 inhibitor, in patients with active moderate to severe Crohn's disease. Inflamm Bowel Dis 2006;12:558-565.

191. Billich A. Drug evaluation: apilimod, an oral IL-12/IL-23 inhibitor for the treatment of autoimmune diseases and common variable immunodeficiency. IDrugs 2007;10:53-59.

192. Gross V, Andus T, Leser HG, Roth M, Scholmerich J. Inflammatory mediators in chronic inflammatory bowel diseases. Klin Wochenschr 1991;69:981-987.

193. Stevens C, et al. Tumor necrosis factor-alpha, interleukin-1 beta, and interleukin-6 
expression in inflammatory bowel disease. Dig Dis Sci 1992;37:818-826.

194. Reinecker HC, et al. Enhanced secretion of tumour necrosis factor-alpha, IL-6, and IL-1 beta by isolated lamina propria mononuclear cells from patients with ulcerative colitis and Crohn's disease. Clin Exp Immunol 1993;94:174-181.

195. Nielsen OH, Kirman I, Rudiger N, Hendel J, Vainer B. Upregulation of interleukin-12 and -17 in active inflammatory bowel disease. Scand J Gastroenterol 2003;38:180-185.

196. Saruta M, Yu QT, Avanesyan A, Fleshner PR, Targan SR, Papadakis KA. Phenotype and effector function of CC chemokine receptor 9-expressing lymphocytes in small intestinal Crohn's disease. J Immunol 2007; 178:3293-3300.

197. Witowski J, et al. Role of mesothelial cellderived granulocyte colony-stimulating factor in interleukin-17-induced neutrophil accumulation in the peritoneum. Kidney Int 2007;71:514-525.

198. Yagi Y, Andoh A, Inatomi O, Tsujikawa T, Fujiyama Y. Inflammatory responses induced by interleukin-17 family members in human colonic subepithelial myofibroblasts. J Gastroenterol 2007;42:746-753.

199. Wolk K, et al. IL-22 induces lipopolysaccharide-binding protein in hepatocytes: a potential systemic role of IL-22 in Crohn's disease. J Immunol 2007; 178:5973-5981.

200. Schwartz S, Beaulieu JF, Ruemmele FM. Interleukin-17 is a potent immuno-modulator and regulator of normal human intestinal epithelial cell growth. Biochem Biophys Res Commun 2005;337:505-509.

201. Caviglia R, Ribolsi M, Rizzi M, Emerenziani S, Annunziata ML, Cicala M. Maintenance of remission with infliximab in inflammatory bowel disease: efficacy and safety long-term follow-up. World J Gastroenterol 2007; 13:5238-5244.

202. Wada Y, et al. Selective abrogation of Th1 response by STA-5326, a potent IL-12/IL23 inhibitor. Blood 2007;109:1156-1164.

203. Pineda AA. Developments in the apheresis procedure for the treatment of inflammatory bowel disease. Inflamm Bowel Dis 2006;12 (Suppl.):S10-S14.

204. Yamamoto T, Nakahigashi M, Umegae S, Kitagawa T, Matsumoto K. Impact of elemental diet on mucosal inflammation in patients with active Crohn's disease: cytokine production and endoscopic and histological findings. Inflamm Bowel Dis 2005; 11:580-588.

205. Taubman MA, Kawai T. Involvement of T-lymphocytes in periodontal disease and in direct and indirect induction of bone resorption. Crit Rev Oral Biol Med 2001;12:125-135.
206. Bartold PM, Marshall RI, Haynes DR. Periodontitis and rheumatoid arthritis: a review. J Periodontol 2005;76:2066-2074.

207. Oda T, Yoshie H, Yamazaki K. Porphyromonas gingivalis antigen preferentially stimulates T cells to express IL-17 but not receptor activator of NF-kappaB ligand in vitro. Oral Microbiol Immunol 2003;18:30-36.

208. Johnson RB, Wood N, Serio FG. Interleukin11 and IL-17 and the pathogenesis of periodontal disease. J Periodontol 2004;75:37-43.

209. Takahashi K, Azuma T, Motohira H, Kinane DF, Kitetsu S. The potential role of interleukin-17 in the immunopathology of periodontal disease. J Clin Periodontol 2005;32:369-374.

210. Vernal R, Dutzan N, Chaparro A, Puente J, Antonieta Valenzuela M, Gamonal J. Levels of interleukin-17 in gingival crevicular fluid and in supernatants of cellular cultures of gingival tissue from patients with chronic periodontitis. J Clin Periodontol 2005;32:383-389.

211. Lester SR, Bain JL, Johnson RB, Serio FG. Gingival concentrations of interleukin-23 and -17 at healthy sites and at sites of clinical attachment loss. J Periodontol 2007; 78:1545-1550.

212. Beklen A, Ainola M, Hukkanen M, Gurgan C, Sorsa T, Konttinen YT. MMPs, IL-1, and TNF are regulated by IL-17 in periodontitis. J Dent Res 2007;86:347-351.

213. Ito $\mathrm{H}$, et al. Gene expression analysis of the CD4+T-cell clones derived from gingival tissues of periodontitis patients. Oral Microbiol Immunol 2005;20:382-386.

214. Colic M, Vasilijic S, Gazivoda D, Vucevic D, Marjanovic M, Lukic A. Interleukin-17 plays a role in exacerbation of inflammation within chronic periapical lesions. Eur J Oral Sci 2007;115:315-320.

215. Yu JJ, et al. An essential role for IL-17 in preventing pathogen-initiated bone destruction: recruitment of neutrophils to inflamed bone requires IL-17 receptordependent signals. Blood 2007; 109:3794-3802.

216. Filipe-Santos $\mathrm{O}$, et al. Inborn errors of IL-12/23 - and IFN-gamma-mediated immunity: molecular, cellular, and clinical features. Semin Immunol 2006;1 18:347-361.

217. Kastelein R, Hunter C, Cua D. Discovery and biology of IL-23 and IL-27: related but functionally distinct regulators of inflammation. Annu Rev Immunol 2007;25:221-242.

218. Minegishi Y, et al. Human tyrosine kinase 2 deficiency reveals its requisite roles in multiple cytokine signals involved in innate and acquired immunity. Immunity 2006;25:745-755.
219. Shibata K, Yamada H, Hara H, Kishihara K, Yoshikai Y. Resident Vdelta 1+ gammadelta $T$ cells control early infiltration of neutrophils after Escherichia coli infection via IL-1 7 production. J Immunol 2007; 178:4466-4472.

220. Witowski J, et al. IL-17 stimulates intraperitoneal neutrophil infiltration through the release of GRO alpha chemokine from mesothelial cells. J Immunol 2000;165:5814-5821.

221. Ley K, Smith E, Stark M. IL-17A-producing neutrophil-regulatory Tn lymphocytes. Immunol Res 2006;34:229-242.

222. Miyamoto M, et al. Neutrophilia in LFA-1deficient mice confers resistance to listeriosis: possible contribution of granulocytecolony-stimulating factor and IL- 17 . J Immunol 2003;1 170:5228-5234.

223. Happel K, et al. Cutting edge: roles of Tolllike receptor 4 and IL-23 in IL-17 expression in response to Klebsiella pneumoniae infection. J Immunol 2003;170:4432-4436.

224. Miyamoto M, Prause O, Sjostrand M, Laan M, Lotvall J, Linden A. Endogenous IL-17 as a mediator of neutrophil recruitment caused by endotoxin exposure in mouse airways. J Immunol 2003;1 170:4665-4672.

225. Ferretti S, Bonneau O, Dubois G, Jones C, Trifilieff A. IL-17, produced by lymphocytes and neutrophils, is necessary for lipopolysaccharide-induced airway neutrophilia: IL-15 as a possible trigger. J Immunol 2003; 170:2106-2112.

226. Shellito J, quan Zheng M, Ye P, Ruan S, Shean $\mathrm{M}$, Kolls J. Effect of alcohol consumption on host release of interleukin-17 during pulmonary infection with Klebsiella pneumoniae. Alcohol Clin Exp Res 2001;25:872-881.

227. Wu Q, Martin R, Rino J, Breed R, Torres R, Chu H. IL-23-dependent IL-17 production is essential in neutrophil recruitment and activity in mouse lung defense against respiratory Mycoplasma pneumoniae infection. Microbes Infect 2007;9:78-86.

228. Higgins S, Jarnicki A, Lavelle E, Mills K. TLR4 mediates vaccine-induced protective cellular immunity to Bordetella pertussis: role of IL-17-producing T cells. J Immunol 2006;177:7980-7989.

229. Chen X, Howard O, Oppenheim J. Pertussis toxin by inducing IL- 6 promotes the generation of IL-17-producing CD4 cells. J Immunol 2007;1 18:6123-6129.

230. Malley R, et al. Antibody-independent, interleukin-17A-mediated, cross-serotype immunity to pneumococci in mice immunized intranasally with the cell wall polysaccharide. Infect Immun 2006;74:2187-2195.

231. Chung D, Chitnis T, Panzo R, Kasper D, Sayegh M, Tzianabos A. CD4+ T cells regulate surgical and postinfectious 
adhesion formation. J Exp Med

2002;195:1471-1478.

232. Chung D, et al. CD4 $+\mathrm{T}$ cells mediate abscess formation in intra-abdominal sepsis by an IL-17-dependent mechanism. J Immunol 2003;1 170:1958-1963.

233. Rice L, et al. CpG oligodeoxynucleotide protection in polymicrobial sepsis is dependent on interleukin-17. J Infect Dis 2005; 191:1368-1376.

234. Hofstetter H, Luhder F, Toyka K, Gold R. IL-17 production by thymocytes upon CD3 stimulation and costimulation with microbial factors. Cytokine 2006;34:184-197.

235. Kim H, et al. Lipoteichoic acid from Lactobacillus plantarum elicits both the production of interleukin-23p19 and suppression of pathogen-mediated interleukin-10 in THP-1 cells. FEMS Immunol Med Microbiol 2007;49:205-214.

236. Kielian T, Haney A, Mayes P, Garg S, Esen N. Toll-like receptor 2 modulates the proinflammatory milieu in Staphylococcus aureusinduced brain abscess. Infect Immun 2005;73:7428-7435.

237. van Beelen A, et al. Stimulation of the intracellular bacterial sensor NOD2 programs dendritic cells to promote interleukin-17 production in human memory T cells. Immunity 2007;27:660-669.

238. Belladonna M, et al. IL-23 neutralization protects mice from Gram-negative endotoxic shock. Cytokine 2006;34:161-169.

239. Ivanov $S$, et al. Functional relevance of the IL-23-IL-17 axis in lungs in vivo. Am J Respir Cell Mol Biol 2007;36:442-451.

240. Dubin P, Kolls J. IL-23 mediates inflammatory responses to mucoid Pseudomonas aeruginosa lung infection in mice. Am J Physiol Lung Cell Mol Physiol 2007;292:L5 19-L528.

241. Luzza F, et al. Up-regulation of IL-17 is associated with bioactive IL- 8 expression in Helicobacter pylori-infected human gastric mucosa. J Immunol 2000;165:5332-5337.

242. Infante-Duarte $C$, Horton $H$, Byrne M, Kamradt T. Microbial lipopeptides induce the production of IL-17 in Th cells. J Immunol 2000;165:6107-6115.

243. Burchill M, et al. Inhibition of interleukin17 prevents the development of arthritis in vaccinated mice challenged with Borrelia burgdorferi. Infect Immun 2003;71:3437-3442.

244. Nardelli D, Burchill M, England D, Torrealba J, Callister S, Schell R. Association of $\mathrm{CD} 4+\mathrm{CD} 25+\mathrm{T}$ cells with prevention of severe destructive arthritis in Borrelia burgdorferi-vaccinated and challenged gamma interferon-deficient mice treated with antiinterleukin-17 antibody. Clin Diagn Lab Immunol 2004;11:1075-1084.
245. Michel M, et al. Identification of an IL-17producing NK1.1 (neg) iNKT cell population involved in airway neutrophilia. J Exp Med 2007;204:995-1001.

246. Butchar J, et al. Francisella tularensis induces IL-23 production in human monocytes. J Immunol 2007; 1 78:4445-4454.

247. Happel K, et al. Pulmonary interleukin-23 gene delivery increases local T-cell immunity and controls growth of Mycobacterium tuberculosis in the lungs. Infect Immun 2005; 73:5782-5788.

248. Khader S, et al. IL-23 compensates for the absence of IL-12p70 and is essential for the IL-17 response during tuberculosis but is dispensable for protection and antigenspecific IFN-gamma responses if IL-12p70 is available. J Immunol 2005; 175:788-795.

249. Feng C, et al. NK cell-derived IFN-gamma differentially regulates innate resistance and neutrophil response in $\mathrm{T}$ cell-deficient hosts infected with Mycobacterium tuberculosis. J Immunol 2006;177:7086-7093.

250. Keller C, Hoffmann R, Lang R, Brandau S, Hermann C, Ehlers S. Genetically determined susceptibility to tuberculosis in mice causally involves accelerated and enhanced recruitment of granulocytes. Infect Immun 2006; 74:4295-4309.

251. Lockhart E, Green A, Flynn J. IL-17 production is dominated by gammadelta $\mathrm{T}$ cells rather than CD4 $\mathrm{T}$ cells during Mycobacterium tuberculosis infection. J Immunol 2006; 177:4662-4669.

252. Chackerian AA, et al. Neutralization or absence of the interleukin-23 pathway does not compromise immunity to mycobacterial infection. Infect Immun 2006;74:6092-6099.

253. Cruz A, et al. Cutting edge: IFN-gamma regulates the induction and expansion of IL-17-producing CD4 T cells during mycobacterial infection. J Immunol 2006;177:1416-1420.

254. Umemura M, et al. IL-17-mediated regulation of innate and acquired immune response against pulmonary Mycobacterium bovis bacille Calmette-Guerin infection. J Immunol 2007;1 78:3786-3796.

255. Wozniak T, Ryan A, Britton W. Interleukin23 restores immunity to Mycobacterium tuberculosis infection in IL-12p40-deficient mice and is not required for the development of IL-17-secreting T cell responses. J Immunol 2006;1 177:8684-8692.

256. Khader S, et al. IL-23 and IL-17 in the establishment of protective pulmonary $\mathrm{CD} 4+\mathrm{T}$ cell responses after vaccination and during Mycobacterium tuberculosis challenge. Nat Immunol 2007;8:369-377.

257. Pathak S, et al. Direct extracellular interaction between the early secreted antigen ESAT-6 of Mycobacterium tuberculosis and TLR2 inhibits TLR signaling in macrophages. Nat Immunol 2007;8:610-618.

258. Kleinschek M, et al. IL-23 enhances the inflammatory cell response in Cryptococcus neoformans infection and induces a cytokine pattern distinct from IL-12. J Immunol 2006;176:1098-1106.

259. Rudner X, Happel K, Young E, Shellito J. Interleukin-23 (IL-23)-IL-17 cytokine axis in murine Pneumocystis carinii infection. Infect Immun 2007;75:3055-3061.

260. Huang W, Na L, Fidel P, Schwarzenberger P. Requirement of interleukin-17A for systemic anti-Candida albicans host defense in mice. J Infect Dis 2004;190:624-631.

261. Zelante T, et al. IL-23 and the Th17 pathway promote inflammation and impair antifungal immune resistance. Eur J Immunol 2007;37:2695-2706.

262. Cooper A. IL-23 and IL-17 have a multifaceted largely negative role in fungal infection. Eur J Immunol 2007;37:2680-2682.

263. LeibundGut-Landmann $S$, et al. Syk- and CARD9-dependent coupling of innate immunity to the induction of $\mathrm{T}$ helper cells that produce interleukin 17. Nat Immunol 2007;8:630-638.

264. Palm N, Medzhitov R. Antifungal defense turns 17. Nat Immunol 2007;8:549-551.

265. Gaddi P, Yap G. Cytokine regulation of immunopathology in toxoplasmosis. Immunol Cell Biol 2007;85:155-159.

266. Rutitzky L, Lopes da Rosa J, Stadecker M. Severe CD4 T cell-mediated immunopathology in murine schistosomiasis is dependent on IL-12p40 and correlates with high levels of IL-17. J Immunol 2005; 175:3920-3926.

267. Fickenscher H, Fleckenstein B. Herpesvirus saimiri. Philos Trans R Soc Lond B Biol Sci 2001;356:545-567.

268. Knappe A, et al. The interleukin-17 gene of Herpesvirus saimiri. J Virol 1998;72:5797-5801.

269. Maertzdorf J, Osterhaus A, Verjans G. IL-17 expression in human herpetic stromal keratitis: modulatory effects on chemokine production by corneal fibroblasts. J Immunol 2002;169:5897-5903.

270. Hashimoto K, et al. Respiratory syncytial virus in allergic lung inflammation increases Muc5ac and gob-5. Am J Respir Crit Care Med 2004;1 70:306-312.

271. Hashimoto K, et al. Respiratory syncytial virus infection in the absence of STAT 1 results in airway dysfunction, airway mucus, and augmented IL-17 levels. J Allergy Clin Immunol 2005; 116:550-557.

272. Smiley K, McNeal M, Basu M, Choi A, Clements J, Ward R. Association of gamma interferon and interleukin-17 production in intestinal CD4 $+\mathrm{T}$ cells with protection against rotavirus shedding in mice 
intranasally immunized with VP6 and the adjuvant LT(R192G). J Virol 2007;81:3740-3748.

273. Dodon M, Li Z, Hamaia S, Gazzolo L. Tax protein of human T-cell leukaemia virus type 1 induces interleukin 17 gene expression in T cells. J Gen Virol 2004;85:1921-1932.

274. Maek-A-Nantawat W, Nantawat W, Buranapraditkun S, Klaewsongkram J, Ruxrungtham K. Increased interleukin-17 production both in helper $\mathrm{T}$ cell subset Th17 and CD4-negative T cells in human immunodeficiency virus infection. Viral Immunol 2007;20:66-75.

275. Wiehler S, Proud D. Interleukin-17A modulates human airway epithelial responses to human rhinovirus infection. Am J Physiol Lung Cell Mol Physiol 2007;293:L505-L515.

276. Patera A, Pesnicak L, Bertin J, Cohen J. Interleukin 17 modulates the immune response to vaccinia virus infection. Virology 2002;299:56-63.

277. Fridman W, Tartour E. Macrophage- and lymphocyte-produced Th1 and Th2 cytokines in the tumour microenvironment. Res Immunol 1998;149:651-653.

278. Kato T, et al. Expression of IL-17 mRNA in ovarian cancer. Biochem Biophys Res Commun 2001;282:735-738.

279. Ciree A, et al. Expression and activity of IL-17 in cutaneous T-cell lymphomas (mycosis fungoides and Sezary syndrome). Int J Cancer 2004;112:113-120.

280. Li M, et al. Thymosinalpha1 stimulates cell proliferation by activating ERK1/2, JNK, and increasing cytokine secretion in human pancreatic cancer cells. Cancer Lett 2007;248:58-67.

281. Haudenschild D, Moseley T, Rose L, Reddi A. Soluble and transmembrane isoforms of novel interleukin-17 receptor-like protein by RNA splicing and expression in prostate cancer. J Biol Chem 2002;277:4309-4316.

282. Umemura M, et al. Involvement of IL-17 in Fas ligand-induced inflammation. Int Immunol 2004;16:1099-1108.

283. Kehlen A, Thiele K, Riemann D, Rainov N, Langner J. Interleukin-17 stimulates the expression of IkappaB alpha mRNA and the secretion of IL-6 and IL-8 in glioblastoma cell lines. J Neuroimmunol 1999;101:1-6.

284. Numasaki $M$, et al. Interleukin-17 promotes angiogenesis and tumor growth. Blood 2003;101:2620-2627.

285. Numasaki M, et al. IL-17 enhances the net angiogenic activity and in vivo growth of human non-small cell lung cancer in SCID mice through promoting CXCR-2dependent angiogenesis. J Immunol 2005; 175:6177-6189.

286. Hirahara N, et al. Inoculation of human interleukin-17 gene-transfected Meth-A fibrosarcoma cells induces $\mathrm{T}$ cell-dependent tumor-specific immunity in mice. Oncology 2001;61:79-89.

287. Benchetrit $F$, et al. Interleukin-17 inhibits tumor cell growth by means of a T-celldependent mechanism. Blood 2002;99:2114-2121.

288. Kryczek I, et al. Cutting edge: Th17 and regulatory $\mathrm{T}$ cell dynamics and the regulation by IL- 2 in the tumor microenvironment. J Immunol 2007; 178:6730-6733.

289. Meeran S, Katiyar S, Elmets C, Katiyar S. Interleukin-12 deficiency is permissive for angiogenesis in UV radiation-induced skin tumors. Cancer Res 2007;67:3785-3793.

290. Langowski J, et al. IL-23 promotes tumour incidence and growth. Nature 2006;442:461-465.

291. Langowski J, Kastelein R, Oft M. Swords into plowshares: IL-23 repurposes tumor immune surveillance. Trends Immunol 2007;28:207-212.

292. Kaiga T, Sato M, Kaneda H, Iwakura Y, Takayama T, Tahara H. Systemic administration of IL-23 induces potent antitumor immunity primarily mediated through Th1-type response in association with the endogenously expressed IL-12. J Immunol 2007; 178:7571-7580.

293. Van Kooten C, et al. Interleukin-17 activates human renal epithelial cells in vitro and is expressed during renal allograft rejection. J Am Soc Nephrol 1998;9:1526-1534.

294. Hsieh H, Loong C, Lui W, Chen A, Lin C. IL-17 expression as a possible predictive parameter for subclinical renal allograft rejection. Transpl Int 2001;14: 287-298.

295. Loong C, Hsieh H, Lui W, Chen A, Lin C. Evidence for the early involvement of interleukin 17 in human and experimental renal allograft rejection. J Pathol 2002;197:322-332.

296. Yoshida S, et al. Anti-type V collagen lymphocytes that express IL-17 and IL-23 induce rejection pathology in fresh and well-healed lung transplants. Am J Transplant 2006;6:724-735.

297. Burlingham W, et al. IL-17-dependent cellular immunity to collagen type $\mathrm{V}$ predisposes to obliterative bronchiolitis in human lung transplants. J Clin Invest 2007;117:3498-3506.

298. Antonysamy M, et al. Evidence for a role of IL-17 in organ allograft rejection: IL-17 promotes the functional differentiation of dendritic cell progenitors. J Immunol 1999;162:577-584.

299. Li J, et al. Gene transfer of soluble interleukin-17 receptor prolongs cardiac allograft survival in a rat model. Eur J Cardiothorac Surg 2006;29:779-783. 